\title{
On the understanding of the effects of sample size on the variability in fracture toughness of bulk metallic glasses
}

\author{
Bernd Gludovatz $^{\mathrm{a}, *}$, Davide Granata ${ }^{\mathrm{b}}$, Keli V. S. Thurston ${ }^{\mathrm{a}, \mathrm{c}}$, Jörg F. \\ Löffler ${ }^{\mathrm{b}}$ and Robert O. Ritchie ${ }^{\mathrm{a}, \mathrm{c}}$ \\ aMaterials Sciences Division, Lawrence Berkeley National Laboratory, Berkeley, California 94720, USA \\ bLaboratory of Metals Physics and Technology, Department of Materials, ETH Zurich, 8093 Zurich, \\ Switzerland \\ 'Department of Materials Science \& Engineering, University of California, Berkeley, California, 94720, USA
}

High strength in combination with improvements in failure characteristics and associated gains in fracture toughness have placed bulk-metallic glasses (BMGs) among the most damage-tolerant materials to date. Recent studies show, however, that there can be large variabilities in the mechanical performance of these alloys, particularly in their toughness, which are likely associated with sample-size effects or structural variations from differences in processing. Here, we examine the variation in fracture toughness of the Pdbased metallic glass $\mathrm{Pd}_{77.5} \mathrm{Cu}_{6} \mathrm{Si}_{16.5}$, using single-edge notched bend specimens but in two different sizes. Although all toughness results on this glass were "valid" in terms of the nonlinear-elastic fracture mechanics J-standard, i.e., one would expect a single value of the fracture toughness for this alloy, marked differences were apparent in the toughness values and failure characteristics of the differently-sized samples. Specifically, significantly larger variations in toughness values were measured in larger-sized samples, which all essentially failed catastrophically, whereas, none of the smaller-sized samples failed catastrophically yet displayed far less scatter in their measured toughness. Additional in-situ tests on the smaller-sized samples in a scanning electron microscope revealed stable crack growth and progressive resistance to crack extension, i.e. rising crack-resistance ( $R$-curve) behavior. Overall, this marked transition from brittle catastrophic failure in large samples where a sizeindependent fracture toughness can be measured, to non-catastrophic, more

* Corresponding author. E-mail: bpgludovatz@lbl.gov 


\section{ductile (R-curve), behavior in smaller samples, the latter associated with higher toughness, was related to the distinct size-dependent bending ductility and strain-softening behavior in BMGs.}

Keywords: bulk metallic glasses; fracture toughness; sample size; strain softening; bending ductility.

\section{Introduction}

Since their introduction in the early 1960s [1], metallic glasses have gained significant attention owing to their exceptional combination of properties such as near-theoretical strength, low stiffness and large elastic strain limits [2-7]. Due to the development of bulk glass-forming alloys [8-10] together with the constantly increasing processing dimensions, bulk metallic glasses (BMGs) are now considered as structural materials [11]. Despite their generally acceptable combination of strength and toughness (i.e., damage tolerance), most glasses exhibit strength levels well above $1.5 \mathrm{GPa}$ with fracture toughness values that are mainly reported to lie between 10 and $100 \mathrm{MPa}^{1 / 2}$ [12-20], the often large variability in mechanical performance, particularly in their fracture and toughness behavior, has been one factor that has compromised their potential use for many structural applications to date. Although some of this variability can be traced to the poor quality of some early BMGs, e.g., there is evidence that certain glasses failed in a highly brittle manner at fracture toughness $K_{\text {Ic }}$ values as low as $\sim 2 \mathrm{MPa}^{1 / 2}$ [21], there are reports of recently developed monolithic and composite BMGs, specifically Pd-based and Zr-based glasses, with fracture toughnesses as high as $\sim 200 \mathrm{MPa}^{1 / 2}$, that have been achieved by promoting ductility through the formation of multiple shear bands, leading to subcritical crack growth and increasing fracture resistance with crack extension, i.e., rising crack-resistance curve ( $R$-curve) behavior [22-25].

To discern the origins of this variability in properties, significant experimental and theoretical efforts are currently underway to improve our understanding of the links between processing, structure and properties in BMGs [5,6,11,26-40]. Aside from these structure-property relationships, which invariably dictate the characteristics and hence 
performance of a material, there also appears to be a strong influence of testing conditions on the mechanical behavior of (certain) metallic glasses. It is known in the glass community, for example, that in strength tests, BMGs typically show local strainsoftening behavior in tension and compression with strain localization often occurring on a single shear band [41-46], whereas in bending, they can conversely demonstrate strain hardening as a result of the formation and multiplication of shear bands (which can be considered as a geometrical effect of this loading condition) [47]. Another influence of testing conditions in BMGs is apparent in their fatigue properties which can display a particularly high susceptibility to the testing environment affecting their fatigue strengths and crack-growth behavior [48-56]. Although environmental effects on a material's fracture toughness are less pronounced, it remains unclear how loading conditions can influence metallic glass samples that contain a crack. While Lewandowski and co-workers have shown that, akin to crystalline materials [57], some of the fracture toughness variability found in the literature can be explained by factors such as the use of notched vs. pre-cracked samples [43,58], we were recently able to attribute some of the variations in the properties of BMGs to a fracture-mechanics based sample-size effect [59]. Specifically, we found that fracture toughness tests on differently sized compact-tension and single-edge notched bend samples of the Zr-based glass

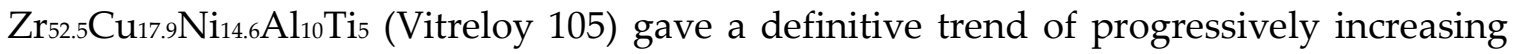
toughness values with decreasing sample size coupled with a wider scatter in the results. We attributed this to the distinct size-dependent bending ductility known from bend tests on plates of various thickness $[60,61]$, and to the strain-softening behavior found for metallic glasses [41-44] which acts to severely limit the extent of the unique Hutchinson-Rice-Rosengren (HRR) crack-tip field that relies on power-law hardening $[62,63]$. In light of this, it appears that although the use of the linear-elastic based $K$ approach, i.e., ASTM standard E399 [64], may be perfectly appropriate for evaluating the toughness of brittle glasses, the corresponding use of the nonlinear-elastic J-integralbased ASTM standard, E1820 [65], may be questionable for high-toughness glasses, 
because of the highly restricted range of crack-tip J-field validity compared to that for strain-hardening crystalline materials.

To provide further insight to the understanding of this complex effect of sample size on the variability of fracture behavior of metallic glasses, we have examined here one specific Pd-based glass in a single test geometry, that of the highly constrained singleedge notched bend geometry, but in two different sizes. Compared to both geometries of the Zr-glass samples in ref. [59], where dimensions were either comparable or well above the glass' critical bending thickness, here we specifically focus on samples that in terms of size range from the Pd-based glass' critical bending thickness to that significantly below this dimension, and compare both the material's fracture toughness and fracture behavior using ASTM recommended sample geometries and size configurations.

\section{Background}

Our analysis of the variability in toughness values in metallic glasses relies on the concept of bending ductility in these materials. After numerous indications of thin wires and foils of amorphous metals showing good ductility in bending [66-73], Katuya et al. [74] and Inoue et al. [75] were first to report that such significant bending ductility in metallic glasses could only be achieved if the thickness of the bent sample was below a critical value; this implied that the bending ductility of glasses is size-dependent. Based on these observation, Conner et al. associated the high ductility in plates of a Zr-based metallic glass subjected to bending to the formation of a large numbers of shear bands $[21,22]$. Specifically, when they tested plates with a thickness, $t$, less than $1.5 \mathrm{~mm}$ that were bent around dies of different radii, $r$, these plates showed an increased propensity for the formation of shear bands, i.e., decreasing shear-band spacing, $\lambda$, and increasing ductility prior to fracture with decreasing plate thickness; the relevant dimensions are shown in Fig. 1. They argued that the much smaller fracture bending strains in thicker plates compared to those measured in thinner ones result from pronounced local strain relaxation in the vicinity of each shear band, thus preventing other shear bands to form 
close to the existing ones; this results in a larger shear band spacing in thicker plates. Since the presence of fewer shear bands leads to more shear deformation accommodated by each individual shear band, the critical shear offset needed to open a shear band and form a crack is reached at lower strains. This ultimately results in a more brittle behavior of thicker metallic glass samples and leads to the conclusion that BMG plates below a certain critical thickness can achieve the relevant number of shear bands to demonstrate significant bending ductility. Whereas the critical bending thickness is a well-known parameter in the metallic glass community and can be readily measured by bending plates of diminishing thickness, to date there is only limited analysis available to predict what this thickness should be.

\section{Experimental procedures and data analysis}

\subsection{Fabrication and characterization of the Pd-based bulk metallic glass}

The Pd-based master alloys were prepared by arc melting high-purity raw materials (Pd 99.95\%, Si 99.9997\%, Cu 99.995\%) according to their atomic ratios in a $6 \mathrm{~N}$ argon atmosphere using an arc melter (Edmund Bühler Labortechnik, Germany). These master alloys were used for the preparation of $\mathrm{Pd}_{77.5} \mathrm{Cu}_{6} \mathrm{Si}_{16.5}$ bulk metallic glasses by flux treatment. The ingots were fluxed with dehydrated boron oxide, $\mathrm{B}_{2} \mathrm{O}_{3}(99.98 \%)$, in quartz tubes and subsequently water-quenched from $1150^{\circ} \mathrm{C}$ to obtain amorphous rods of $8 \mathrm{~mm}$ diameter. The cyclic heating-cooling treatment associated with fluxing was performed for eight fluxing cycles between $300^{\circ} \mathrm{C}$ and $1150^{\circ} \mathrm{C}$ with an overall fluxing time of 24 hours. A detailed description of the fluxing procedure is provided in our preceding publications $[76,77]$.

The amorphous structure of the glass was verified by $\mathrm{x}$-ray diffraction, XRD, using a

Stoe STADI x-ray diffractometer in Bragg-Brentano geometry. Similarly, all thermal characteristics of the glass were verified by means of differential scanning calorimetry, DSC, (Netzsch DSC 404 C Pegasus) at a heating rate of $20 \mathrm{~K} . \mathrm{min}^{-1}$ (Fig. 2); DSC revealed a glass-transition temperature, $T_{\mathrm{g}}=625 \mathrm{~K}$, a crystallization temperature, $T_{\mathrm{x}}=698 \mathrm{~K}$, a solidus temperature, $T_{\mathrm{s}}=1015 \mathrm{~K}$, and a liquidus temperature, $T_{1}=1080 \mathrm{~K}$. 


\subsection{Sample preparation and mechanical testing}

Two groups of single-edge notched bend, SE(B), samples were prepared from rods of diameter $d=8 \mathrm{~mm}$, in general accordance with ASTM standards E399 and E1820 $[64,65]$ using electrical discharge machining, EDM, with a wire of $0.1 \mathrm{~mm}$ diameter. ${ }^{+}$One group, the larger-sized standard sample group (L-samples), had a cross section (thickness, $B \times$ width, $W$ ) of roughly $3.5 \times 6 \mathrm{~mm}^{2}(W / B \sim 2)$ whereas the smaller-sized alternative sample group (S-samples) had a $B \times W$ of $\sim 3.2 \times 3.2 \mathrm{~mm}^{2}(W / B \sim 1)$. Samples were notched using EDM along the sample width to about $W / 2$ and, except for three Lsamples, all other samples were additionally micro-notched using a razor blade while constantly being irrigated with a water-based diamond compound. To remove any damage from the EDM cutting process, two sides of all samples were gradually polished to a $\sim 1 \mu \mathrm{m}$ surface finish with silicon carbide grinding papers. To prevent premature failure, all samples were initially pre-cracked in compression at a constant frequency, $f$, of $25 \mathrm{~Hz}$ (sine wave) and an $R$ of 10, where $R$ is the ratio of minimum to maximum applied load, $P_{\min } / P_{\max }$, using an electro servo-hydraulic MTS 810 load frame (MTS Corporation, Eden Prairie, MN, USA) controlled with an Instron 8800 digital controller (Instron Corporation, Norwood, MA, USA). Subsequently, the pre-cracks were extended in tension using a three-point bending setup with loading spans, $S$, of $15 \mathrm{~mm}$ and $10 \mathrm{~mm}$ for the larger and smaller samples, respectively; $\Delta K$-levels were between $\sim 4-7.5$ MPa.m ${ }^{1 / 2}$, the $R$-ratio was 0.1 , and the same frequency used for the initiation of the precracks was used for their extension. Except for one of the L-samples which was only notched, the length of the resulting pre-cracks was in all cases at least 1.5 times the notch-root radius and therefore well outside any stress concentration resulting from the notch $[78,79]$. The sample with the shorter pre-crack is marked in Table 1, the length of the pre-crack was roughly about the size of the notch root radius. Final crack length, $a$, to width ratios, $a / W$, were in the range $0.41-0.55$ and hence in close accordance with the ASTM standard E399 [64] requirement of $a / W=0.45-0.55$, leaving initial ligament widths,

\footnotetext{
$\dagger$ Because the stress-state in the $\mathrm{SE}(\mathrm{B})$ and $\mathrm{C}(\mathrm{T})$ geometries is essentially similar, in that they impose highlyconstrained, primarily bending conditions, we have focused here solely on the SE(B) geometry.
} 
$b$, of $\sim 3 \mathrm{~mm}$ and $\sim 1.5 \mathrm{~mm}$ for the larger standard and the smaller alternative samples, respectively. In total, eleven $(N=11)$ samples, five $(N=5)$ L-samples and six $(N=6) \mathrm{S}$ samples, were prepared for testing; a detailed summary of all sample dimensions can be found in Table 1.

The five L-samples were tested in three-point bending, with $S=24 \mathrm{~mm}$, at a constant displacement rate of $1 \mu \mathrm{m} . \mathrm{s}^{-1}$ using the same equipment used for pre-cracking. Three of the S-samples (S1-S3) were tested using a screw-driven Instron 5944 testing machine (Instron Corporation, Norwood, MA, USA) in a three-point bending setup with $S=12$ $\mathrm{mm}$. The other three S-samples (S4-S6) were tested in situ in a Hitachi S-4300SE/N scanning electron microscope, SEM (Hitachi America, Pleasanton, CA), using a Gatan MicroTest $2 \mathrm{kN}$ bending stage (Gatan, Abingdon, UK) at a displacement rate of 0.55 $\mu \mathrm{m} . \mathrm{s}^{-1}$ and with a loading span of $S=12 \mathrm{~mm}$. In these tests, the crack length, $a$, on the surface of the samples was monitored in regular intervals together with the crack-tip opening displacement (CTOD), $\delta$, which was evaluated from crack-opening displacements (COD) measured at the root of the razor-notch behind the pre-crack, to incorporate any plastic deformation that may occur through shear banding behind the crack tip of the pre-crack. The measured COD values were used to compute the crack-tip CTOD values, consistent with Tracey's 45 degree intercept definition of the CTOD [80], using the usual assumption of rotation of the bend samples about a hinge point at the distance $r(W-a)$ ahead of the crack tip, where $(W-a)$ is the uncracked ligament and $r$ is the so-called rotational factor, given as 0.44 for the three-point bend geometry [81-83].

\subsection{Data analysis and statistics}

To determine the fracture toughness of the glass, both sample groups were characterized in general accordance with ASTM Standard E399 [64]. Conditional fracture toughness, $K_{\mathrm{Q}}$-values, were calculated from $P_{\mathrm{Q}}$-loads taken from i) the intersection of the 95\% secant lines with the non-linear elastic parts of the load-displacement, $P-v$, curves for samples that failed with significant amounts of plastic deformation (type I failure), ii) the maximum loads for samples that showed pop-ins within the $95 \%$ secant line (type II 
failure), or iii) the maximum loads for samples that showed minor plasticity and catastrophic failure within the 95\% secant line (type III failure). All tests were verified in terms of validity criteria for size-independent plane-strain fracture toughness testing, i.e. $P_{\max } / P_{\mathrm{Q}}<1.1$ and $a, B, b>2.5\left(K_{\mathrm{Q}} / \sigma_{\mathrm{y}}\right)^{2}$, where $\sigma_{\mathrm{y}}$ is the yield strength of the material which has been determined from individual tensile tests on tensile specimens with a gauge length of $20 \mathrm{~mm}$ and a gauge cross section of $2 \mathrm{~mm}$ diameter at a strain rate of $3 \times$ $10^{-4} \mathrm{~s}^{-1}$. The value of the yield strength in this alloy was found to be $1520 \mathrm{MPa}$, comparable to results in the literature [84]).

To further characterize the extreme variations in the fracture behavior of the glass, data from samples of both groups were additionally analyzed using the nonlinear-elastic J-based ASTM Standard E1820 [65] which allows for incorporating the role of plastic deformation in the determination of the material's fracture toughness. Conditional fracture toughness, $K_{\mathrm{JQ}}$-values, were determined from $J_{\mathrm{Q}}$-values of each sample taken from instabilities, i.e., the first pronounced load drops, $P_{\mathrm{JQ}}$, in the load-(crosshead) displacement, $P-v$ curves. Specifically, the $J$-integral was computed as the sum of elastic, $J_{\mathrm{el}}$, and plastic components, $J_{\mathrm{pl}}$, such that at the individual load-drops the Je-integral can be written as follows:

$$
J_{\mathbf{Q}}=K^{2} / E^{\prime}+J_{\mathrm{pl}}
$$

where $E^{\prime}=E$, Young's modulus, in-plane stress and $E^{\prime}=E /\left(1-v^{2}\right)$ in-plane strain; $v$ is Poisson's ratio. Values of $E=89 \mathrm{GPa}$ and $v=0.41$ were taken from ref. [17] and verified using resonant ultrasound spectroscopy. $K$, the linear-elastic stress intensity, was calculated from:

$$
K=\frac{P S}{B W^{3 / 2}} f(a / W)
$$

where $P$ is the load at instability and $f(a / W)$ a geometry-dependent function of the crack length to width ratio provided in the standard [65]. The plastic component of $J$ is calculated as:

$$
J_{\mathrm{pl}}=\frac{\eta A_{\mathrm{pl}}}{B b}
$$


where $\eta=1.9$ for the $\mathrm{SE}(\mathrm{B})$ geometry and $A_{\mathrm{pl}}$ the plastic area underneath the $P-v$ curve. Conditional fracture toughness values expressed in terms of the stress intensity, $\mathrm{K}_{\mathrm{JQ}}-$ values, were then back-calculated using the standard $J-K$ equivalence (mode I) relationship $K_{\mathrm{JQ}}=\left(J_{\mathrm{Q}} E^{\prime}\right)^{1 / 2}$ assuming plane-strain conditions. All results were verified in terms of the most stringent ASTM E1820 [65] criterion for fracture toughness values determined from instabilities, i.e., $B, b_{0}>\left(100 J_{\mathrm{Q}} / \sigma_{\mathrm{o}}\right)$, where $\sigma_{\mathrm{o}}$ is the flow stress given by the mean of the yield, $\sigma_{\mathrm{y}}$, and tensile, outs, strengths $\left(\sigma_{\mathrm{y}}=\sigma \mathrm{ts}=\sigma_{\mathrm{o}}=1520 \mathrm{MPa}\right)$. Results were additionally validated in terms of the maximum $J$-integral capacity of a specimen, which requires $B, b_{0}>\left(10 J \mathrm{Q} / \sigma_{\mathrm{o}}\right)[65]$.

While all samples were evaluated in terms of linear-elastic fracture mechanics, Jintegral based fracture toughness data at instabilities could only be determined for Lsamples that showed type I failure with load-drops occurring only after significant amounts of plasticity (L1, L4, L5), whereas samples S2 and S4 were the only two of the smaller-sized S-samples that showed load-drops in their P-v curves. (A summary of (failure) loads, $P_{\mathrm{Q}}, P_{\mathrm{JQ}}, P_{\max }$ for calculating conditional fracture toughness values, $K_{\mathrm{Q}}$ and $K_{\mathrm{JQ}}$, the ratio of $P_{\max } / P_{\mathrm{Q}}$, and failure types of all samples are shown in Table 1.)

Statistical analysis of the data was achieved by performing an analysis of variances (ANOVA) test to determine which means were statistically different from each other with $p<0.05$ being considered statistically significant. To compare the in situ SEM tested alternative samples with respect to the ones that were tested ex situ on external testing machines, an additional $t$-test was performed individually.

\subsection{Additional characterization}

Akin to ref. [24], crack-resistance curves (R-curves) were additionally calculated for the smaller-sized alternative samples that were tested in situ in the SEM. At each increment of crack extension, $\Delta a, J$-values were calculated from:

$$
J=\frac{1}{d_{n}} \sigma_{\mathbf{o}} \delta_{t},
$$


where $\delta_{\mathrm{t}}=\delta_{\mathrm{i}}-\delta_{\mathrm{o}}$, with $\delta$ the instantaneous CTOD and $\delta_{0}$ the initial CTOD. Furthermore, $\sigma_{\mathrm{o}}$ is the flow stress and $d_{\mathrm{n}}$ is a constant, varying between 0.3 and 1 , which is a function of the strain-hardening exponent, $n$, and yield strain, $\sigma_{\circ} / E$, of the material and whether plane-strain or plane-stress conditions apply [85]. Based on the comparable strength and the assumptions made for the Pd-glass in ref. [24], and the fact that identical geometry and similar sample sizes were used, the same $n \sim 0.13$ was chosen. Resulting $J$-values were translated into stress intensities and plotted as $K_{\mathrm{J}}-\Delta a$ curves using the standard $K-J$ equivalence.

Finally, after testing, fracture surfaces of samples that failed catastrophically were fractographically analyzed in the SEM using the secondary electron imaging mode.

\section{Results}

Table 1 lists all fracture toughness results determined from the $P-v$ curves of both sample groups (Fig. 3) using both the linear-elastic and nonlinear-elastic fracture standards [64,65]. The means and standard deviations of the individual groups are additionally shown as a function of sample size in terms of ligament width, $b$, in Fig. 4a, whereas Fig. $4 \mathrm{~b}$ shows the R-curves that were calculated from the in situ SEM tests. While all large-sized L-samples (with $b \sim 3 \mathrm{~mm}$ ) showed significant load drops during testing (Fig. 3a), only two of them (samples L1 and L2) failed catastrophically, whereas samples L3 and L5 remained somewhat intact and sample L4 failed catastrophically but with crack initiation far from behind the pre-crack and the razor notch (this latter result was accordingly excluded from further analysis). In comparison, none of the smallersized S-samples (with $b \sim 1.5 \mathrm{~mm}$ ) failed catastrophically even though the loads on sample S2 and on the in situ tested sample S4 dropped significantly during testing, as shown in Fig. 3b. (Open symbols are used here for all L-samples and for the three ex situ tested S-samples; to make the data more distinguishable, the $P-v$ data of the in situ tested S-samples are shown using lines only).

\subsection{Linear-elastic and elastic-plastic analysis}


Using the linear-elastic ASTM standard E399 [64], the conditional fracture toughness, $K_{\mathrm{Q}}$, of standard samples L1 and L5 was calculated using P $P_{\mathrm{Q}}$-loads from the intersect of the $95 \%$ secant line with the $P-v$ curves of the corresponding samples (type I failure) and found to be 67.7 MPa.m ${ }^{1 / 2}$ and $86.4 \mathrm{MPa}^{1 / 2}$, respectively. The loads of samples L2 and L3 that occurred right before their load drops yielded $K_{\mathrm{Q}}$-values of $6.9 \mathrm{MPa} \cdot \mathrm{m}^{1 / 2}$ and 5.1 MPa.m ${ }^{1 / 2}$, respectively; the load-drops of both samples occurred within the $95 \%$ secant lines and were considered significant so that sample L2 was characterized as failure type III and sample L3 as failure type II. All smaller-sized S-samples showed type I failure and their $K_{\mathrm{Q}}$-values were calculated between $\sim 46-65 \mathrm{MPa} \cdot \mathrm{m}^{1 / 2}$, the precise value of each sample is listed in Table 1. Of all samples from both groups, only sample L2 fulfilled all validity criteria to qualify as linear-elastic fracture toughness, $K_{\mathrm{IC}}$, so that nonlinearelastic fracture mechanics methods, in general accordance with ASTM standard E1820 [65], were applied and where possible, the plastic deformation was incorporated into the calculation of the samples' fracture toughnesses determined at the first significant load drop in their $P-v$ curves. This yielded $K_{\mathrm{JQ}}$-values of $82.9 \mathrm{MPa}^{1 / 2}$ and $100.4 \mathrm{MPa}^{1 / 2}$ for samples L1 and L5, respectively; neither of these two failure type I samples fulfilled the $P_{\max } / P_{\mathrm{Q}}<1.1$ requirement for valid linear-elastic fracture toughness (LEFM) testing. As the load drops of samples L2 and L3 occurred within the 95\% secant lines, plastic deformation in these samples was considered to be negligible and hence $K_{\mathrm{JQ}}$-values were not evaluated. None of the smaller sized S-samples failed catastrophically and all of them were well above the $P_{\max } / P_{\mathrm{Q}}<1.1$ requirement; $K_{\mathrm{JQ}}$-values, however, could only be calculated for the two samples that showed significant load-drops during testing. Their conditional $K_{\mathrm{JQ}}$-values were 129.4 MPa.m ${ }^{1 / 2}$ for sample S2 and $105.8 \mathrm{MPa} \cdot \mathrm{m}^{1 / 2}$ for the in situ tested sample S4.

All nonlinear-elastic fracture toughness values measured in this study met the ASTM Standards E1820 [65] criteria for J-field dominance and plane strain of $B, b_{0}>\left(10 J \mathrm{~J} / \sigma_{\mathrm{o}}\right)$, i.e., all samples met the maximum J-integral capacity size requirement. However, none met the most stringent size criterion for fracture toughness testing specifically determined at fracture instability. 


\subsection{Statistics}

As shown in Fig. 4a, the four large-sized standard samples (L-samples) resulted in an average conditional fracture toughness, $K_{Q}$ of $41.5 \mathrm{MPa} \cdot \mathrm{m}^{1 / 2}$ with a standard deviation of $36.1 \mathrm{MPa} \cdot \mathrm{m}^{1 / 2}$ when determined using linear-elastic fracture mechanics; using nonlinear-elastic methods, $K_{\mathrm{JQ}}$ was calculated to be $91.6 \pm 8.7 \mathrm{MPa} \cdot \mathrm{m}^{1 / 2}$. Means and standard deviations of the six smaller-sized alternative samples (S-samples) were calculated as $K_{\mathrm{Q}}=57.0 \pm 7.1 \mathrm{MPa}^{1 / 2}$ and $K_{\mathrm{JQ}}=117.6 \pm 11.8 \mathrm{MPa}^{1 / 2}$. The ANOVA test yielded no statistically significant differences $(p>0.05)$ between the linear-elastic $K_{Q}$ results and the nonlinear-elastic $K_{\mathrm{JQ}}$ results within both sample groups, between the two sample groups with respect to each other, and between the KQ-values of the ex situ tested samples S1-S3 and the in situ tested samples S4-S6 of the small-sized alternative group. The individual, simple $t$-test between the KQ-values of samples S1-S3 and samples S4-S6, however, found a statistically significant difference with $p=0.037$.

\subsection{Crack-resistance curves (R-curves)}

Shih's computed relationship [85], based on the HRR crack-tip field [62,63], was employed to relate crack-tip opening displacements, CTODs, to the corresponding Jvalues; these were then converted to equivalent stress-intensity $K_{\mathrm{J}}$ values using the standard mode I $J-K$ equivalence, which in combination with the crack extension, $\Delta a$, recorded during in situ testing of the three alternative samples, enabled the determination of full crack-resistance curves (R-curves), plotted in Fig. 4b. $¥$ Crackinitiation toughness values were found to be $150 \mathrm{MPa}^{1 / 2}$; crack-growth toughness values were as high as $\sim 250-400 \mathrm{MPa} \cdot \mathrm{m}^{1 / 2}$ after crack extensions of approximately $\sim 500$ $\mu \mathrm{m}$.

\footnotetext{
\$ While Shih's J-CTOD relationship is strictly valid only until the initiation of a crack, J-controlled crack growth, JR-curves and CTOD R-curves, provide a valuable means to describe a material's fracture behavior (using the assumption of nonlinear elastic (not plastic) fracture mechanics) and are qualified in the ASTM 1820 Standard in terms of the assumption of the existence of an HRR field, which incidentally is also the sole basis of Shih's J-CTOD relationship. Accordingly, we expect little error in the use of this relationship provided the crack growth R-curve data remain within ASTM's bounds of J-field validity. Further confirmation that this relationship is appropriate beyond the onset of the initiation of a crack can be seen where the slope of the CTOD R-curve with crack extension, i.e., the crack-tip opening angle (CTOA), remains essentially unchanged with crack advance.
} 


\section{Discussion}

\subsection{Failure characterization}

In contrast to our previous study [59] on a Zr-based glass, where smaller samples displayed significantly more variation in fracture toughness than samples with larger ligament width, $b$, the fracture toughness values of the larger-sized L-samples in the current study on the $\mathrm{Pd} 77.5 \mathrm{Cu}_{6} \mathrm{Si}_{16.5}$ glass were found to vary significantly more than the values from the smaller-sized S-samples of the alternative group, as shown in Fig. 4a. This is particularly true for the KQ-values of the L-samples where significant toughness variations resulted from the different failure modes of the individual samples, as described below and in Fig. 5; conversely, the fracture behavior of individual S-samples in the smaller-sized alternative group was essentially similar (Figs. 6 and 7).

To highlight these extreme variations in fracture toughness values for the standard group, samples L1 and L2 are compared in Figs. 5a,b. On the one hand, sample L1 failed catastrophically with significant crack deflections starting from pronounced shear-lips at the notch leading to a highly tortuous crack path out of the mode I plane, resulting in a conditional fracture toughness, $K_{\mathrm{Q}}$, of $67.7 \mathrm{MPa}^{1 / 2}$ (Fig. 5a). Sample L2, on the other hand, showed mode I crack propagation without significant crack-path deviations resulting in a $K_{Q}$ of only $6.9 \mathrm{MPa} \cdot \mathrm{m}^{1 / 2}$. Despite the significant load drops shown in Fig. 3a, the other two standard samples, L3 and L5, did not fail catastrophically and remained somewhat intact (Figs. 5c,d). While both samples showed relatively large CTODs, sample L3 displayed a somewhat more serrated but overall straight crack path (Fig. 5c), resulting in a surprisingly low $K_{\mathrm{Q}}$ of $5.1 \mathrm{MPa} \cdot \mathrm{m}^{1 / 2}$ despite pronounced shear banding at the crack tip and bifurcation at first crack extensions. In stark contrast, sample L5 failed with extreme crack deflection out of the mode I plane and slightly curved crack front throughout the sample thickness (Fig. 5d); this led to an order of magnitude higher toughness value of $K_{Q}=86.4 \mathrm{MPa}^{1 / 2}$. Clearly, crack path deviations seem to have a much more pronounced influence on the measured fracture toughness values than shear banding through bifurcation at the crack tip. It is an understatement to 
say that it is highly unusual that the fracture toughness of a given metallic alloy, measured in a fixed geometry, should vary so widely, specifically between 5 and 86 MPa.m ${ }^{1 / 2}$. This becomes even more worrisome for the nonlinear-elastic results which admittedly scattered slightly less, i.e., between 50 and $100 \mathrm{MPa} \cdot \mathrm{m}^{1 / 2}$ for the large-sized samples. However, it is important to note that these J-based results were all measured with "valid" specimen sizes and thus would be expected to give the same fracture toughness value for this material. Moreover, the "valid" nonlinear-elastic fracture toughness of the smaller-sized samples further increased this variability, with fracture toughness values as high as $\sim 130 \mathrm{MPa} \cdot \mathrm{m}^{1 / 2}$.

There are several possible reasons for this substantial scatter in the measured toughness of metallic glasses. Variabilities in the short-range order in the amorphous state $[33,34,86]$ and the possible highly limited existence of the HRR crack-tip field were pointed out as two reasons in ref. [59] to explain the variation in fracture toughness in a Zr-based glass. Here we focus on an additional issue, that of the critical bending ductility in metallic glasses $[60,61]$, to explain the vastly different fracture toughness results in the current $\mathrm{Pd}_{77.5} \mathrm{Cu}_{6} \mathrm{Si}_{16.5}$ BMG. Below a certain composition-specific sample thickness, metallic glasses loaded in bending have an increasing propensity, progressively with decreasing sample thickness, to form an increasing number of narrower-spaced shear bands; this results in their capacity to inhibit catastrophic failure through the formation of multiple stable shear bands. We find that this is very much the case in the current Pd-glass. Larger L-samples, with ligament widths of $b \sim 3 \mathrm{~mm}$, seem to be on the verge of this critical bending ductility thickness where shear bands cannot reliably develop to the full extent; accordingly, during the formation of multiple shear bands, one band can become prematurely unstable causing large differences in failure characteristics and significant variations in the measured toughness. Sample L3, for example, showed shear-band formation ahead of the crack leading to crack bifurcation, as can clearly be seen on the surface of the sample in Fig. 5c; none of the other samples in that group showed such behavior. Conversely, the smaller S-samples, with ligament widths of $b \sim 1.5 \mathrm{~mm}$, are clearly below the critical bending thickness of this glass, 
resulting in pronounced shear banding and fully ductile failure characteristics of all samples. As shown in Fig. 6, samples S1-S3 show significant formation and proliferation of shear bands from the root of both the notch and the pre-crack throughout their entire ligament width causing extremely large plastic zones, widely open crack mouths, and correspondingly, enormous CTODs. ${ }^{\S}$ Such pronounced shear banding, together with the additional formation of shear bands towards the back of the samples (Figs. 6a,b,d), acts to promote excessive necking through contractions in the tension region ahead of the crack tip and protrusions at the back of the sample where compressive stresses occur (Fig. 6d). Although the extent of these failure characteristics, particularly the contractions and protrusions, reveal a lack of constraint associated with the testing of such smaller-sized Pd-glasses (with the result that the fracture toughness values can become inflated), at the same time these values show less variability due to the reliably fully-ductile failure characteristics of each sample, as evidenced by the linear-elastic KQvalues of 62.3, 64.2 and $64.0 \mathrm{MPa}^{1 / 2}$ for the small-sized samples S1, S2 and S3, respectively. Clearly, the measured fracture toughness values of this metallic glass, although "valid" in terms of $J$, are still sample-size dependent.

While the tests on the smaller-sized alternative samples (Fig. 6) clearly show that using undersized metallic glass samples can help to prevent or at least delay catastrophic failure, the pronounced extension of the crack in sample S2 (Fig. 6b) compared to the other two samples in this group, and the associated load-drop in its corresponding $\mathrm{P}-\mathrm{v}$ curve (Fig. $3 \mathrm{~b}$ ), require a better understanding of the mechanisms underlying deformation and crack propagation in this material. Accordingly, three additional small-sized samples, S4-S6, were step-loaded in situ in an SEM and the evolution of shear bands and extension of the existing pre-crack monitored.

Overall, the mode of failure of these additional samples was very similar to that in samples S1-S3, as shown in Fig. 7. Sample S4 (Fig. 7a) showed pronounced crack

$\S$ Note that samples S4-S6 of the alternative group were not included in this comparison as during in situ testing, the loading was stopped frequently to permit crack-length measurements (for $R$-curve determination). Samples S1-S3, conversely, were loaded quasi-statically and thus are directly comparable to the results from the large-sized standard group. 
bifurcation starting from a single pre-crack leading to a large CTOD of several hundred micrometers associated with the easy formation of shear bands in wake of the crack, a slightly curved crack front throughout the thickness of the sample, and a significant drop in the $P-v$ response (Fig. $3 b$ ) when one of the bifurcated cracks extended toward the back of the sample. Sample S5 (Fig. 7b) formed multiple cracks even though none of them became as dominant and extended as far as the major crack in sample S4. Sample S5 had a straight crack front throughout the material and the resulting large CTODs caused pronounced contractions and protrusions. In comparison, the crack in sample S6 (Fig. 7c) tunneled in the center of the sample significantly further than it extended on the surface. This sample showed somewhat less contractions and protrusions but similar to sample S4, the crack front in the center of the sample was significantly curved. Although slightly lower than the values of the alternative samples S1-S3, the measured fracture toughness values from these in situ tests also showed only a modest variability with linear-elastic fracture toughness results of $K_{\mathrm{Q}}=49.9 \mathrm{MPa}^{1 / 2}, 55.6 \mathrm{MPa}^{1 / 2}$ and 46.0 MPa.m ${ }^{1 / 2}$ for samples S4, S5 and S6, respectively, because of the fully ductile failure characteristics that can reliably develop in such smaller-sized samples through excessive shear banding.

\subsection{Statistical analysis}

Even though neither the differences between the $K_{\mathrm{Q}}$ and the $K_{\mathrm{JQ}}$-values of both sample groups individually nor with respect to each other were statistically significant, this should not be interpreted as definitive proof of no sample-size effect between the groups. Rather, this missing statistical significance has likely to be associated with the large variation in the linear-elastic $K_{\mathrm{Q}}$ data of the larger samples and the small number and hence missing statistical power of the nonlinear-elastic $K_{\mathrm{JQ}}$ data. ${ }^{* *}$ By comparison, the statistical significance $(p<0.05)$ of the $t$-test between the in situ and ex situ tested S-

\footnotetext{
** We have chosen the first drop in the $P$-v curves, i.e., instabilities, for calculating a conditional nonlinearelastic fracture toughness of each sample. Although some of these instabilities might not be significant, any other subsequent choice of load would result in higher fracture toughness results, a disproportionate increase in the $K_{J Q}$-values, and likely an increasing scatter resulting from the varying amounts of plasticity that occurred for the individual samples.
} 
samples might result from the use of a different loading-rig or the differences in loading conditions, i.e., step-loading vs. quasi-static loading.

\subsection{In situ characterization}

The evolution of the specific failure modes in the in situ tested samples is shown in Fig. 8 for sample 66 from the small-sized sample group. Before loading, the notch, razornotch and the pre-crack were all clearly distinguishable, as shown in Fig. 8a, which also reveals the opening of the pre-crack via shear bands emanating from the root of the crack at a load of $\sim 375 \mathrm{~N}$ (first shear-band formation was observed to occur at $2200 \mathrm{~N}$ ). At a load of $\sim 680 \mathrm{~N}$, significant formation and proliferation of shear bands was observed from both the root and the wake of the pre-crack (insets of Fig. 8b). At the maximum load of $\sim 800 \mathrm{~N}$, shear bands started to additionally form at the back of the sample (Fig. 8b) leading to large CTODs at the root of the former pre-crack (inset of Fig. 8c), pronounced shear of multiple individual shear bands behind the pre-crack (resulting in shear-band offsets), and the formation of an increasing plastic-zone size (Fig. 8c). ${ }^{+{ }^{+t}}$ At a load of $\sim 730 \mathrm{~N}$, past the load maximum, the sample had an extensive plastic zone with shear bands in the back of the sample generating macroscopic shear offsets (Fig. 8d). Upon further straining, which caused the load to decrease to $\sim 500 \mathrm{~N}$, the sample showed fully plastic behavior with shear bands now occurring throughout the ligament with extended shear-band offsets in the back of the sample (Fig. 8e); at this point, crack extension occurred through a stick-slip mechanism [89], the source of stability of crack growth, simultaneously at multiple locations, tearing open and thereby extending the crack (inset of Fig. 8c). $¥$ The resulting stable crack extension leads to an extremely large

\footnotetext{
+t Compared to the arrangement of the shear bands in the plastic zone ahead of the crack tip that is reminiscent of the Green-Hundy fully plastic slip-line field theory [87], the shear bands that form in the unnotched, bent samples in Conner's work do not resemble a typical Prandtl stress field [88] but instead are significantly more inclined and extending - at least in some cases - mainly in one direction. Reasons for these differences might be associated with asymmetric bending, a different critical thickness of the glass, or the different stresses resulting from the stress concentration at the root of the notch.
}

¥ Conner et al. has shown that the stress state as a result of the bending radius clearly correlates with the number of shear bands that form and what failure type a glass shows. As such, failure within the critical bending thickness clearly depends on specific sample dimensions, the stresses ahead of the crack tip and 
CTOD of several hundred micrometers and clearly shows that the formation and offset of multiple shear bands in this Pd-based glass is energetically more favorable than the propagation of a crack when testing such smaller-sized samples. Fig. 8f depicts the sample right before finishing the test at a final load of $\sim 425 \mathrm{~N}$ with a final crack extension of less than $300 \mu \mathrm{m}$ on the sample surface and a CTOD of more than half a millimeter. At this point, the sample is clearly fully plastic.

$R$-curves, calculated for samples S4-S6, gave crack-initiation toughness values of $\sim 150 \mathrm{MPa} \cdot \mathrm{m}^{1 / 2}$ and crack-growth toughness values (at crack extensions of $\sim 500 \mu \mathrm{m}$ ) of 250-400 MPa.m ${ }^{1 / 2}$ (Fig. 4b). $₫ \S$ Despite the variability in these results which are likely associated with variations in the crack path of the samples, these are significantly higher numbers for the $\mathrm{Pd} \mathrm{d}_{77.5} \mathrm{Cu}_{6} \mathrm{Si}_{16.5}$ glass than earlier results for a $\mathrm{Pd}{ }_{79} \mathrm{Ag}_{3.5} \mathrm{P}_{6} \mathrm{Si}_{9.5} \mathrm{Ge}_{2}$ glass [24], despite their similar strain-hardening exponent and comparable strength. We believe that this primarily results from the larger critical bending thickness of the Pd-based glass used in this study, as compared to the glass used in ref. [24]; this results in larger CTODs (inset of Fig. 4b) despite the larger ligament width. ${ }^{* * *}$

As noted in ref. [59], the absence of significant strain hardening in metallic glasses [24,90] implies that the development of unique (HRR) crack-tip stress and displacement fields under elastic-plastic deformation conditions may not always be realized in BMGs. This together with the issue of the critical bending ductility discussed here brings into question the utility of nonlinear-elastic fracture mechanics to reliably define the fracture

\footnotetext{
throughout the ligament of the sample, and the properties of the glass itself. Structural variations, however, might influence the formation of shear bands and add a stochastic component to the failure type.

$\S \S$ Despite the validity issues with $J-K$ conversions and $K$-based $R$-curves in the present study, the large variation in numbers resulting from analyzing the data in terms of $J$ - despite those numbers being valid in terms of sample size requirements according to ASTM - led us to not just use one single method but characterize the material regarding its $R$-curve behavior with a simultaneous data analysis according to ASTM standard E399. This should underline that a single-value fracture toughness in terms of $K$ does often not tell the whole "story" of the toughness of a material.
}

\footnotetext{
*** Additionally, we noted a small calculation error in ref. [24] in the determination of the toughness of the Pd79Ag ${ }_{3.5} \mathrm{P}_{6} \mathrm{Si}_{9.5} \mathrm{Ge}_{2}$ glass, specifically from the use of Shih's J-CTOD equivalence relationship [85], which caused the magnitude of the fracture toughness and the $R$-curves in this study to be underestimated by approximately $40 \%$.
} 
toughness of the tougher metallic glasses. Nevertheless, despite this potential uncertainty in measurement methodology, it is abundantly clear that many BMGs, in particularly those such as the Pd-based glasses, which have the capability of generating significant plasticity from multiple shear-band formation [21], still possess exceptional damage tolerance (strength and fracture resistance), although these properties may only be truly realized in section sizes below the critical bending thickness.

Despite the possibility that our results may be affected by subjective interpretation of the data and that the marked sample-size dependence suggests that a single (sizeindependent) fracture toughness may not be definable for this Pd-glass, we believe that based on the findings of this study, in combination with the results in ref. [59], it is apparent that metallic glasses have a brittle failure region where, if material can be processed in appropriately large sections, the true linear-elastic, plane-strain fracture toughness of the material can be determined, as shown in Fig. 9. At smaller scales, when a glass is processed to dimensions where the ligament width in a fracture toughness test is comparable with, or at least within a certain range of the critical bending thickness of this glass, the measured fracture toughness values may display higher numbers, show increased variability, and become sample-size and geometry-dependent. Below this critical bending thickness, as shown here and in refs. [24,25], the glass will likely exhibit fully ductile failure characteristics in a fracture toughness test but with less variability in the results and, due to the abundant shear-band plasticity, exhibit $R$-curve behavior in the form of non-catastrophic failure and subcritical crack growth. Only tests performed on samples with dimensions significantly above the critical bending thickness of a glass can yield fracture toughness values that are size-independent and "valid" with respect to current ASTM standards, and hence should result in significantly reduced scatter.

\section{Conclusions}

The fracture properties of the $\mathrm{Pd}_{77.5} \mathrm{Cu}_{6} \mathrm{Si}_{16.5}$ metallic glass have been investigated with the aim of understanding the large variability in fracture toughness values in BMGs. Following on from an earlier study on a Zr-based glass [59], we used single-edge 
notched bend specimens with two different sizes to investigate the effects of sample size on the mechanistic failure modes and fracture toughness behavior of metallic glasses. Based on this work, the following specific conclusions can be made:

- Large-sized ASTM standard samples, termed L-samples, with a ligament width that is comparable to the critical bending thickness of the glass, show large variability in their failure characteristics ranging from brittle fracture behavior with low fracture toughness values to the activation of pronounced shear banding and crack bifurcation, the latter resulting in highly deviated crack paths and an excessive variability in the measured fracture toughness values.

- Smaller-sized ASTM alternative samples, termed S-samples, with uncracked ligament sizes well below the critical bending thickness of this glass, show consistent failure characteristics with pronounced formation and proliferation of multiple shear bands from both the pre-crack and the root of the notch throughout the samples. This leads to marked contractions ahead of the crack tip and protrusion in the back of the samples, resulting in significantly higher fracture toughness values compared to the larger-sized samples but also less scatter in the data as a result of fully ductile failure characteristics.

- In situ tests of the smaller-sized alternative samples performed in the SEM revealed a statistically significant difference in the linear-elastic KQ-values compared to same-size samples that were tested ex situ. These in situ tests show the evolution of shear bands throughout the ligament of the samples resulting in extremely large plastic-zone sizes, pronounced crack-tip opening displacements, the formation of cracks through 'tearing' and, subsequently, stable crack growth with increasing resistance to crack propagation, i.e., rising $R$-curve behavior. Using nonlinear-elastic fracture mechanics, fracture toughness values were calculated from the measured crack-tip opening displacements and found to be $\sim 150 \mathrm{MPa}^{1 / 2}$ at crack initiation rising to $\sim 250-400 \mathrm{MPa}^{1 / 2}$ at crack extensions of $\sim 500 \mu \mathrm{m}$. 
- In combination with the findings in ref. [59], our results suggest that metallic glasses show a transition in fracture behavior that is linked to their sample size. Samples with ligament widths larger than the critical bending thickness show brittle failure characteristics and low fracture toughness values with only small variations in the results; in this regime, the true linear-elastic plane-strain $K_{\text {Ic }}$ fracture toughness of the material can be determined. Tests on samples with dimensions comparable to the critical bending thickness yield highly variable, sample-size and geometry-dependent fracture toughness results whereas samples that are below the critical bending thickness can show fully ductile failure characteristics, less variability in the results, and non-catastrophic failure with sub-critical crack growth and $R$-curve behavior.

- Although all toughness data determined in this work for the $\mathrm{Pd}{ }_{77.5} \mathrm{Cu}_{6} \mathrm{Si}_{16.5}$ bulk metallic glass meet the ASTM specimen size validity requirements for crack-tip Jfield dominance and plane strain, fracture toughness values still show extreme variability. In general, results from metallic glass samples that were tested with ligament widths that are either comparable or below the critical bending thickness of that specific glass, including the fracture toughness numbers obtained in this study, should be considered sample-size and likely geometrydependent. Use of a sample with a ligament and thickness dimension that exceeds this critical bending thickness is mandatory as an additional requirement in order to determine a size- and geometry-independent fracture toughness of a metallic glass.

\section{Acknowledgments}

This research was primarily supported through the Mechanical Behavior of Materials Program (KC13) at the Lawrence Berkeley National Laboratory by the U.S. Department of Energy, Office of Science, Office of Basic Energy Sciences, Materials Sciences and Engineering Division under contract no. DE-AC02-05CH11231, and by the Swiss National Science Foundation (SNF Grant No. 200020-153103). The authors would 
like to thank Dr. Davide Risso for help with the statistical analysis of the results and Erwin Fischer for support during sample preparation.

\section{References}

[1] W. Klement, R.H. Willens, P. Duwez, Non-crystalline Structure in Solidified GoldSilicon Alloys, Nature. 187 (1960) 869-870.

[2] C.J. Byrne, M. Eldrup, Bulk Metallic Glasses, Science. 321 (2008) 502-503.

[3] A. Inoue, T. Zhang, T. Masumoto, Al-La-Ni Amorphous Alloys with a Wide Supercooled Liquid Region, Mater. Trans. JIM. 30 (1989) 965-972.

[4] A. Inoue, H. Yamaguchi, T. Zhang, T. Masumoto, Al-La-Cu Amorphous Alloys with a Wide Supercooled Liquid Region, Mater. Trans. JIM. 31 (1990) 104-109.

[5] J.F. Löffler, Bulk metallic glasses, Intermetallics. 11 (2003) 529-540.

[6] J. Schroers, The superplastic forming of bulk metallic glasses, JOM J. Miner. Met. Mater. Soc. 57 (2005) 35-39.

[7] M.F. Ashby, A.L. Greer, Metallic glasses as structural materials, Scr. Mater. 54 (2006) 321-326.

[8] H.W. Kui, A.L. Greer, D. Turnbull, Formation of bulk metallic glass by fluxing, Appl. Phys. Lett. 45 (1984) 615-616.

[9] A. Peker, W.L. Johnson, A highly processable metallic glass: Zr41.2Ti13.8Cu12.5Ni10.0Be22.5, Appl. Phys. Lett. 63 (1993) 2342-2344.

[10] A. Inoue, Stabilization of metallic supercooled liquid and bulk amorphous alloys, Acta Mater. 48 (2000) 279-306.

[11] J.J. Kruzic, Bulk Metallic Glasses as Structural Materials: A Review, Adv. Eng. Mater. 18 (2016) 1308-1331.

[12] C.J. Gilbert, R.O. Ritchie, W.L. Johnson, Fracture toughness and fatigue-crack propagation in a Zr-Ti-Ni-Cu-Be bulk metallic glass, Appl. Phys. Lett. 71 (1997) 476-478.

[13] C.J. Gilbert, V. Schroeder, R.O. Ritchie, Mechanisms for fracture and fatigue-crack propagation in a bulk metallic glass, Metall. Mater. Trans. A. 30 (1999) 1739-1753.

[14] K.M. Flores, R.H. Dauskardt, Enhanced toughness due to stable crack tip damage zones in bulk metallic glass, Scr. Mater. 41 (1999) 937-943.

[15] J. Schneibel, J. Horton, P. Munroe, Fracture toughness, fracture morphology, and crack-tip plastic zone of a Zr-based bulk amorphous alloy, Metall. Mater. Trans. A. 32 (2001) 2819-2825. 
[16] K.M. Flores, W.L. Johnson, R.H. Dauskardt, Fracture and fatigue behavior of a Zr$\mathrm{Ti}-\mathrm{Nb}$ ductile phase reinforced bulk metallic glass matrix composite, Scr. Mater. 49 (2003) 1181-1187.

[17] J.J. Lewandowski, W.H. Wang, A.L. Greer, Intrinsic plasticity or brittleness of metallic glasses, Philos. Mag. Lett. 85 (2005) 77-87.

[18] M.E. Launey, R. Busch, J.J. Kruzic, Effects of free volume changes and residual stresses on the fatigue and fracture behavior of a $\mathrm{Zr}-\mathrm{Ti}-\mathrm{Ni}-\mathrm{Cu}-\mathrm{Be}$ bulk metallic glass, Acta Mater. 56 (2008) 500-510.

[19] X.J. Gu, S.J. Poon, G.J. Shiflet, J.J. Lewandowski, Compressive plasticity and toughness of a Ti-based bulk metallic glass, Acta Mater. 58 (2010) 1708-1720.

[20] S.L. Philo, J. Heinrich, I. Gallino, R. Busch, J.J. Kruzic, Fatigue crack growth behavior of a Zr58.5Cu15.6Ni12.8Al10.3Nb2.8 bulk metallic glass-forming alloy, Scr. Mater. 64 (2011) 359-362.

[21] C.H. Shek, G.M. Lin, K.L. Lee, J.K.L. Lai, Fractal fracture of amorphous Fe46Ni32V2Si14B6 alloy, J. Non-Cryst. Solids. 224 (1998) 244-248.

[22] D.C. Hofmann, J.-Y. Suh, A. Wiest, G. Duan, M.-L. Lind, M.D. Demetriou, W.L. Johnson, Designing metallic glass matrix composites with high toughness and tensile ductility, Nature. 451 (2008) 1085-1089.

[23] M.E. Launey, D.C. Hofmann, J.-Y. Suh, H. Kozachkov, W.L. Johnson, R.O. Ritchie, Fracture toughness and crack-resistance curve behavior in metallic glass-matrix composites, Appl. Phys. Lett. 94 (2009) 241910-241910-3.

[24] M.D. Demetriou, M.E. Launey, G. Garrett, J.P. Schramm, D.C. Hofmann, W.L. Johnson, R.O. Ritchie, A damage-tolerant glass, Nat. Mater. 10 (2011) 123-128.

[25] Q. He, J.K. Shang, E. Ma, J. Xu, Crack-resistance curve of a Zr-Ti-Cu-Al bulk metallic glass with extraordinary fracture toughness, Acta Mater. 60 (2012) 49404949.

[26] C.A. Schuh, T.C. Hufnagel, U. Ramamurty, Mechanical behavior of amorphous alloys, Acta Mater. 55 (2007) 4067-4109.

[27] J. Schroers, Processing of Bulk Metallic Glass, Adv. Mater. 22 (2010) 1566-1597.

[28] W. Dmowski, Y. Yokoyama, A. Chuang, Y. Ren, M. Umemoto, K. Tsuchiya, A. Inoue, T. Egami, Structural rejuvenation in a bulk metallic glass induced by severe plastic deformation, Acta Mater. 58 (2010) 429-438.

[29] Y.Q. Cheng, E. Ma, Atomic-level structure and structure-property relationship in metallic glasses, Prog. Mater. Sci. 56 (2011) 379-473.

[30] E. Axinte, Metallic glasses from "alchemy" to pure science: Present and future of design, processing and applications of glassy metals, Mater. Des. 35 (2012) 518-556. 
[31] P. Tandaiya, R. Narasimhan, U. Ramamurty, On the mechanism and the length scales involved in the ductile fracture of a bulk metallic glass, Acta Mater. 61 (2013) 1558-1570.

[32] B. Gludovatz, M.D. Demetriou, M. Floyd, A. Hohenwarter, W.L. Johnson, R.O. Ritchie, Enhanced fatigue endurance of metallic glasses through a staircase-like fracture mechanism, Proc. Natl. Acad. Sci. 110 (2013) 18419-18424.

[33] J. Ding, S. Patinet, M.L. Falk, Y. Cheng, E. Ma, Soft spots and their structural signature in a metallic glass, Proc. Natl. Acad. Sci. 111 (2014) 14052-14056.

[34] E. Ma, Tuning order in disorder, Nat. Mater. 14 (2015) 547-552.

[35] L. Krämer, K.S. Kormout, D. Setman, Y. Champion, R. Pippan, Production of Bulk Metallic Glasses by Severe Plastic Deformation, Metals. 5 (2015) 720-729.

[36] S.V. Ketov, Y.H. Sun, S. Nachum, Z. Lu, A. Checchi, A.R. Beraldin, H.Y. Bai, W.H. Wang, D.V. Louzguine-Luzgin, M.A. Carpenter, A.L. Greer, Rejuvenation of metallic glasses by non-affine thermal strain, Nature. 524 (2015) 200-203.

[37] R. Narasimhan, P. Tandaiya, I. Singh, R.L. Narayan, U. Ramamurty, Fracture in metallic glasses: mechanics and mechanisms, Int. J. Fract. (2015) 1-23.

[38] R.L. Narayan, P. Tandaiya, G.R. Garrett, M.D. Demetriou, U. Ramamurty, On the variability in fracture toughness of "ductile" bulk metallic glasses, Scr. Mater. 102 (2015) 75-78.

[39] Y. Tong, T. Iwashita, W. Dmowski, H. Bei, Y. Yokoyama, T. Egami, Structural rejuvenation in bulk metallic glasses, Acta Mater. 86 (2015) 240-246.

[40] T.C. Hufnagel, C.A. Schuh, M.L. Falk, Deformation of metallic glasses: Recent developments in theory, simulations, and experiments, Acta Mater. 109 (2016) 375393.

[41] F. Spaepen, A microscopic mechanism for steady state inhomogeneous flow in metallic glasses, Acta Metall. 25 (1977) 407-415.

[42] P.S. Steif, F. Spaepen, J.W. Hutchinson, Strain localization in amorphous metals, Acta Metall. 30 (1982) 447-455.

[43] J.J. Lewandowski, M. Shazly, A. Shamimi Nouri, Intrinsic and extrinsic toughening of metallic glasses, Scr. Mater. 54 (2006) 337-341.

[44] J. Pan, Q. Chen, L. Liu, Y. Li, Softening and dilatation in a single shear band, Acta Mater. 59 (2011) 5146-5158.

[45] R. Maaß, D. Klaumünzer, J.F. Löffler, Propagation dynamics of individual shear bands during inhomogeneous flow in a Zr-based bulk metallic glass, Acta Mater. 59 (2011) 3205-3213.

[46] R. Maaß, J.F. Löffler, Shear-Band Dynamics in Metallic Glasses, Adv. Funct. Mater. 25 (2015) 2353-2368. 
[47] Q. He, J. Xu, Locating Malleable Bulk Metallic Glasses in Zr-Ti-Cu-Al Alloys with Calorimetric Glass Transition Temperature as an Indicator, J. Mater. Sci. Technol. 28 (2012) 1109-1122.

[48] V. Schroeder, C.J. Gilbert, R.O. Ritchie, Effect of aqueous environment on fatiguecrack propagation behavior in a Zr-based bulk amorphous metal, Scr. Mater. 40 (1999) 1057-1061.

[49] V. Schroeder, C.J. Gilbert, R.O. Ritchie, A comparison of the mechanisms of fatiguecrack propagation behavior in a Zr-based bulk amorphous metal in air and an aqueous chloride solution, Mater. Sci. Eng. A. 317 (2001) 145-152.

[50] V. Schroeder, R.O. Ritchie, Stress-corrosion fatigue-crack growth in a Zr-based bulk amorphous metal, Acta Mater. 54 (2006) 1785-1794.

[51] M.L. Morrison, R.A. Buchanan, P.K. Liaw, B.A. Green, G.Y. Wang, C.T. Liu, J.A. Horton, Corrosion-fatigue studies of the Zr-based Vitreloy 105 bulk metallic glass, Mater. Sci. Eng. A. 467 (2007) 198-206.

[52] A. Wiest, G. Wang, L. Huang, S. Roberts, M.D. Demetriou, P.K. Liaw, W.L. Johnson, Corrosion and corrosion fatigue of Vitreloy glasses containing low fractions of late transition metals, Scr. Mater. 62 (2010) 540-543.

[53] L. Huang, G. Wang, D. Qiao, P.K. Liaw, S. Pang, J. Wang, T. Zhang, Corrosionfatigue study of a Zr-based bulk-metallic glass in a physiologically relevant environment, J. Alloys Compd. 504, Supplement 1 (2010) S159-S162.

[54] S.E. Naleway, R.B. Greene, B. Gludovatz, N.K.N. Dave, R.O. Ritchie, J.J. Kruzic, A Highly Fatigue-Resistant Zr-Based Bulk Metallic Glass, Metall. Mater. Trans. A. 44 (2013) 5688-5693.

[55] L.Y. Watanabe, S.N. Roberts, N. Baca, A. Wiest, S.J. Garrett, R.D. Conner, Fatigue and corrosion of a Pd-based bulk metallic glass in various environments, Mater. Sci. Eng. C. 33 (2013) 4021-4025.

[56] Y. Wang, Y. Liu, L. Liu, Fatigue Behaviors of a Ni-free ZrCuFeAlAg Bulk Metallic Glass in Simulated Body Fluid, J. Mater. Sci. Technol. 30 (2014) 622-626.

[57] R.O. Ritchie, B. Francis, W.L. Server, Evaluation of toughness in AISI 4340 alloy steel austenitized at low and high temperatures, Metall. Trans. A. 7 (1976) 831-838.

[58] P. Lowhaphandu, J.J. Lewandowski, Fracture toughness and notched toughness of bulk amorphous alloy: Zr-Ti-Ni-Cu-Be, Scr. Mater. 38 (1998) 1811-1817.

[59] B. Gludovatz, S.E. Naleway, R.O. Ritchie, J.J. Kruzic, Size-dependent fracture toughness of bulk metallic glasses, Acta Mater. 70 (2014) 198-207.

[60] R.D. Conner, W.L. Johnson, N.E. Paton, W.D. Nix, Shear bands and cracking of metallic glass plates in bending, J. Appl. Phys. 94 (2003) 904-911.

[61] R.D. Conner, Y. Li, W.D. Nix, W.L. Johnson, Shear band spacing under bending of Zr-based metallic glass plates, Acta Mater. 52 (2004) 2429-2434. 
[62] J.W. Hutchinson, Singular behaviour at the end of a tensile crack in a hardening material, J. Mech. Phys. Solids. 16 (1968) 13-31.

[63] J.R. Rice, G.F. Rosengren, Plane strain deformation near a crack tip in a power-law hardening material, J. Mech. Phys. Solids. 16 (1968) 1-12.

[64] E08 Committee, E399-12e3 Standard Test Method for Linear-Elastic Plane-Strain Fracture Toughness KIc of Metallic Materials, West Coshohocken, PA: ASTM International, 2012.

[65] E08 Committee, E1820-15a Standard Test Method for Measurement of Fracture Toughness, West Coshohocken, PA: ASTM International, 2015.

[66] N.L. Petouhoff, A.J. Ardell, A.F. Jankowski, Mechanical behaviour of both sides of an amorphous Fe78B14Si8 alloy ribbon as determined from miniaturized disk-bend tests, Acta Metall. Mater. 40 (1992) 3167-3177.

[67] S. Suto, K. Matsuno, T. Sano, K. Matsui, Bending of amorphous alloys, J. Mater. Process. Technol. 33 (1992) 215-227.

[68] Inoue, A., Amiya, K., Yoshii, I., Kimura, H. M., Masumoto, T., Production of AlBased Amorphous Alloy Wires with High Tensile Strength by a Melt Extraction Method, Mater. Trans. JIM. 35 (1994) 485-488.

[69] Inoue, Akihisa, Amiya, Kenji, Katsuya, Akihiro, Masumoto, Tsuyoshi, Mechanical Properties and Thermal Stability of Ti- and Al-Based Amorphous Wires Prepared by a Melt Extraction Method, Mater. Trans. JIM. 36 (1995) 858-865.

[70] E.P. Barth, F. Spaepen, R. Bye, S.K. Das, Influence of processing on the ductile-tobrittle transition temperature of an Fe-B-Si metallic glass, Acta Mater. 45 (1997) 423-428.

[71] A. Katsuya, A. Inoue, T. Masumoto, Production and properties of amorphous alloy wires in Fe-B base system by a melt extraction method, Mater. Sci. Eng. A. 226 (1997) 104-107.

[72] A. Inoue, X.M. Wang, Bulk amorphous FC20 (Fe-C-Si) alloys with small amounts of $\mathrm{B}$ and their crystallized structure and mechanical properties, Acta Mater. 48 (2000) 1383-1395.

[73] Y. Yokoyama, K. Yamano, K. Fukaura, H. Sunada, A. Inoue, Enhancement of Ductility and Plasticity of Zr55Cu30Al10Ni5 Bulk Glassy Alloy by Cold Rolling, Mater. Trans. JIM. 42 (2001) 623-632.

[74] A. Katsuya, A. Inoue, K. Amiya, Production of Ni-Si-B amorphous alloy wires by melt extraction and their thermal and mechanical-properties, Int. J. Rapid Solidif. 9 (1996) 137-158.

[75] A. Inoue, A. Katsuya, K. Amiya, T. Masumoto, Preparation of Amorphous Fe-Si-B and Co-Si-B Alloy Wires by a Melt Extraction Method and Their Mechanical and Magnetic Properties, Mater. Trans. JIM. 36 (1995) 802-809. 
[76] D. Granata, E. Fischer, V. Wessels, J.F. Löffler, Fluxing of Pd-Si-Cu bulk metallic glass and the role of cooling rate and purification, Acta Mater. 71 (2014) 145-152.

[77] D. Granata, E. Fischer, V. Wessels, J.F. Löffler, The detrimental effect of fluxinduced boron alloying in Pd-Si-Cu bulk metallic glasses, Appl. Phys. Lett. 106 (2015) 11902.

[78] N.E. Dowling, W.K. Wilson, Results of elastic analysis of bluntly notched compact specimens, Eng. Fract. Mech. 20 (1984) 569-572.

[79] T. Fett, D. Munz, Influence of narrow starter notches on the initial crack growth resistance curve of ceramics, Arch. Appl. Mech. 76 (2006) 667-679.

[80] D.M. Tracey, Finite Element Solutions for Crack-Tip Behavior in Small-Scale Yielding, J. Eng. Mater. Technol. 98 (1976) 146-151.

[81] T. Ingham, G.R. Egan, D. Elliott, T.C. Harrison, Conf Pract. Appl. Fract. Mech. Press. Vessel Technol. Inst. Mech. Eng. 200 (1971).

[82] D. Elliott, E.F. Walker, M.J. May, Conf Pract. Appl. Fract. Mech. Press. Vessel Technol. Inst. Mech. Eng. 217 (1971).

[83] R.F. Smith, Ph.D. Thesis, The University of Cambridge, 1971.

[84] X.K. Xi, D.Q. Zhao, M.X. Pan, W.H. Wang, Y. Wu, J.J. Lewandowski, Fracture of Brittle Metallic Glasses: Brittleness or Plasticity, Phys. Rev. Lett. 94 (2005) 125510.

[85] C.F. Shih, Relationships between the J-integral and the crack opening displacement for stationary and extending cracks, J. Mech. Phys. Solids. 29 (1981) 305-326.

[86] J. Zemp, M. Celino, B. Schönfeld, J.F. Löffler, Crystal-Like Rearrangements of Icosahedra in Simulated Copper-Zirconium Metallic Glasses and their Effect on Mechanical Properties, Phys. Rev. Lett. 115 (2015) 165501.

[87] A.P. Green, B.B. Hundy, Initial plastic yielding in notch bend tests, J. Mech. Phys. Solids. 4 (1956) 128-144.

[88] R. Hill, Mathematical Theory of Plasticity, 1950.

[89] D. Klaumünzer, R. Maaß, J.F. Löffler, Stick-slip dynamics and recent insights into shear banding in metallic glasses, J. Mater. Res. 26 (2011) 1453-1463.

[90] G.N. Yang, Y. Shao, K.F. Yao, The shear band controlled deformation in metallic glass: a perspective from fracture, Sci. Rep. 6 (2016) 21852. 
Table 1: Summary of sample dimensions, testing conditions, (failure) loads, $P_{\mathrm{Q}}, P_{\mathrm{JQ}}, P_{\max }$ for calculating conditional fracture toughness values, $K_{\mathrm{Q}}$ and $K_{\mathrm{JQ}}$, and ratio of $P_{\max } / P_{\mathrm{Q}}$. Additionally, the failure types according to ASTM Standard E399 of the tested larger-sized standard and smaller-sized alternative single-edge notched bend, $\mathrm{SE}(\mathrm{B}), \mathrm{Pd} 77.5 \mathrm{Cu}_{6} \mathrm{Si}_{16.5}$ metallic glass samples are shown.

\begin{tabular}{|c|c|c|c|c|c|c|c|c|c|c|}
\hline & Sample & & $\begin{array}{l}W \\
{[\mathrm{~mm}]}\end{array}$ & $\begin{array}{l}B \\
{[\mathrm{~mm}]}\end{array}$ & $\begin{array}{l}a / W \\
{[-]} \\
\end{array}$ & $\begin{array}{l}b \\
{[\mathrm{~mm}]}\end{array}$ & $\begin{array}{l}P_{\mathrm{Q}} / P_{\mathrm{JQ}} / P_{\max ^{\dagger+\dagger}} \\
{[\mathrm{N}]}\end{array}$ & $\begin{array}{l}P_{\max } / P_{Q} \\
\text { ratiott+ [-] }\end{array}$ & $\begin{array}{l}K_{\mathrm{Q}} / K_{\mathrm{JQ}^{+}}{ }^{t++} \\
{\left[\mathrm{MPa} . \mathrm{m}^{1 / 2}\right]}\end{array}$ & $\begin{array}{l}\text { Failure type }{ }^{t+t} \\
\text { (ASTM E399) }\end{array}$ \\
\hline \multirow{6}{*}{$\begin{array}{l}\text { Large-sized standard } \\
\text { samples (L-samples) } \\
(b \sim 3 \mathrm{~mm}, W / B \sim 2)\end{array}$} & $\mathrm{L} 1 \neq \pm \ddagger, \S \S \S, * * * * *$ & ex situ & 6.00 & 3.54 & 0.41 & 3.54 & $2281 / 2534$ / 2960 & 1.30 & 67.7 / 82.9 & I \\
\hline & $\mathrm{L} 2^{* * * *}$ & ex situ & 6.00 & 3.52 & 0.46 & 3.26 & 202 / - / 202 & 1.00 & $6.9 /-$ & III \\
\hline & L3\$ss,t+t+ & ex situ & 6.04 & 3.54 & 0.44 & 3.40 & 159 / - / 641 & 4.03 & $5.1 /-$ & II \\
\hline & L4\$s§, & ex situ & 6.01 & 3.44 & 0.42 & 3.49 & 1229 / $1401 / 1401$ & 1.14 & $38.5 / 49.5$ & I \\
\hline & L5\$\$\&,***** & ex situ & 6.04 & 3.44 & 0.43 & 3.42 & 2663 / 2875 / 3031 & 1.14 & 86.4 / 100.4 & I \\
\hline & & & & & & & \multicolumn{2}{|c|}{ Mean \pm standard deviation: } & \multicolumn{2}{|c|}{$41.5 \pm 36.1 / 91.6 \pm 8.7$} \\
\hline \multirow{7}{*}{$\begin{array}{l}\text { Small-sized } \\
\text { alternative samples } \\
\text { (S-samples) } \\
(b \sim 1.5 \mathrm{~mm}, W / B \sim 1)\end{array}$} & $S 1 \S \& \& \&$ & ex situ & 3.00 & 3.17 & 0.51 & 1.48 & 995 / - / 1273 & 1.28 & $62.3 /-$ & I \\
\hline & $\mathrm{S} 2$ & ex situ & 3.22 & 3.22 & 0.54 & 1.40 & $951 / 1136$ / 1147 & 1.21 & 64.2 / 129.4 & I \\
\hline & S3sss\& & ex situ & 3.11 & 3.11 & 0.53 & 1.41 & 925 / - / 1135 & 1.23 & $64.0 /-$ & I \\
\hline & $\mathrm{S} 4^{* * * * *}$ & in situ & 3.20 & 3.20 & 0.51 & 1.47 & 796 / 979 / 979 & 1.23 & 49.9 / 105.8 & I \\
\hline & $\mathrm{S} 5 \S \S \S \S, * * * * * *$ & in situ & 3.10 & 3.10 & 0.53 & 1.42 & 808 / - / 994 & 1.23 & $55.6 /-$ & I \\
\hline & $\mathrm{S} 6 \$ \S \S \S, * * * * * *$ & in situ & 3.18 & 3.18 & 0.54 & 1.40 & $676 /-/ 805$ & 1.19 & 46.0 / - & I \\
\hline & & & & & & & \multicolumn{2}{|c|}{ Mean \pm standard deviation: } & \multicolumn{2}{|c|}{$57.0 \pm 7.1 / 117.6 \pm 11.8$} \\
\hline
\end{tabular}

\footnotetext{
${ }^{+++}$In general accordance with ASTM Standard E 399 [64], KQ values were determined from PQ-loads taken from the intersection of the 95\% secant lines with the non-linear elastic parts of the load-displacement curves. Except for standard sample L2 which showed type III failure $\left(P_{\mathrm{Q}}=P_{\mathrm{max}}\right)$, none of the samples fulfilled the $P_{\max } / P_{\mathrm{Q}} \leq 1.1$ requirement; thus, elastic-plastic fracture toughness, $K_{\mathrm{JQ}}$, measurements were applied as recommended by the E 399 Standard. $K_{\mathrm{JQ}}$ values were determined at $P_{\mathrm{JQ}}$ loading points which were selected at the first significant load drops in the corresponding load-displacement, $P$ - $v$, curves for each sample.

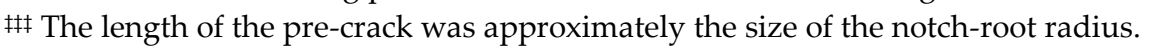

s\& Samples with $a / W<0.45$.

**** Samples without razor-notch.

${ }^{++t+}$ The first significant load drop of standard sample L3 which showed type II failure occurred within the 95\% secant line; KJQ was hence not determined.

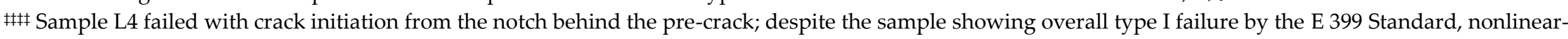
elastic fracture toughness values were not determined and the sample was excluded from mean \pm standard deviation calculations.

s§§ As these samples did not show any significant load drops, KJQ values were not determined.

****** In situ refers to tests conducted inside the SEM with real-time fracture imaging; ex situ refers to tests conducted on an external testing machine.
} 


\section{Figure Captions}

Figure 1. Bending ductility of bulk metallic glasses. Conner et al. [21,22] have shown that below a certain critical thickness, $t$, the spacing of shear bands, $\lambda$, in bulk metallic glass (BMG) samples decreases with increasing bending moment, $M$, and decreasing radius, $r$. This enables BMGs to prevent catastrophic failure through the formation of multiple shear bands resulting in increasing ductility in bending with decreasing thickness. (Figure taken from ref. [59].)

Figure 2. X-ray diffraction (XRD) analysis and differential scanning calorimetry (DSC) of the Pd77.5 $\mathrm{Cu}_{6} \mathrm{Si}_{16.5}$ metallic glass. a, XRD performed at $0.5^{\circ}$ per minute showed the fully amorphous nature of the Pd77.5 $\mathrm{Cu}_{6} \mathrm{Si}_{16.5}$ BMG. $\mathbf{b}$, DSC of the glass performed at a heating rate of $20 \mathrm{~K} \cdot \mathrm{min}^{-1}$ revealed a glass-transition temperature, $T_{\mathrm{g}}=625 \mathrm{~K}$, a crystallization temperature, $T_{\mathrm{x}}=698 \mathrm{~K}$, and a solidus, $T_{\mathrm{s}}=1015 \mathrm{~K}$, and liquidus temperature, $T_{1}=1080 \mathrm{~K}$.

Figure 3. Load-displacement, $P-v$, curves of the Pd-based glass using large-sized standard and small-sized alternative single-edge notched bend, SE(B), samples. a, The $P-v$ data of five standard L-samples showed a wide range of failure characteristics from almost ideally linear-elastic failure to significant amounts of plasticity before failure; after multiple load drops final fracture loads were found between about $100 \mathrm{~N}$ (see inset) and more than 3000 N. b, Despite significant load drops of the ex situ loaded sample S2 and the SEM in situ loaded sample S4, none of the six alternative S-samples failed catastrophically.

Figure 4. Fracture toughness of the Pd-based BMG samples. a, Mean fracture toughness values of both L-samples and S-samples were significantly lower when calculated using linear-elastic fracture mechanics $\left(K_{\mathrm{Q}}\right)$, as compared to their corresponding nonlinear-elastic fracture toughness values, KJQ. b, In situ SEM-tested Ssamples showed subcritical crack growth with crack-tip opening displacements (CTODs) up to $1 \mathrm{~mm}$ (see inset) and an increasing crack propagation resistance with crack extension ( $R$-curve behavior).

Figure 5. Failure modes of the large-size standard samples. a, Sample L1 failed catastrophically with a highly tortuous crack path whereas $\mathbf{b}$, sample L2 showed a relatively smooth fracture surface along the mode I crack propagation plane. c, Sample L3 did not fail catastrophically; it displayed a serrated but overall straight crack path and showed relatively large CTODs. d, Sample L5, while also not failing catastrophically, showed extreme crack deflection out of the mode I plane and a slightly curved crack front throughout the thickness of sample L5.

Figure 6. Failure modes of the ex situ tested small-sized alternative samples. a, Sample S1 showed significant formation and proliferation of shear bands from the root of both the notch and the pre-crack. $\mathbf{b}$, Sample S2 showed similar features with the additional formation and propagation of a crack. c, In the case of sample S3, the excessive shear 
banding resulted in pronounced shear-offset-lips at first crack extensions leading to $\mathbf{d}$, excessive necking through contractions ahead of the crack tip and protrusions at the back of the sample.

Figure 7. Failure modes of the in situ SEM tested small-sized alternative samples. a, Sample S4 failed by the formation of pronounced crack bifurcation starting from a single pre-crack leading to large CTODs and a slightly curved crack front throughout the thickness of the sample. $\mathbf{b}$, Crack extension in sample S5 occurred through the formation of multiple cracks with very large CTODs and pronounced contractions and protrusions. c, Sample S6 showed significant crack tunneling in the center of the sample and a pronounced curvature of the crack front.

Figure 8. Evolution of failure in the in situ tested sample S6. a, The onset of shear-band formation for the pre-cracked sample occurred around $200 \mathrm{~N}$ before $\mathbf{b}$, shear bands formed both in the back of the sample and from the root of the razor-notch at a load of $\sim 800 \mathrm{~N}$, leading to $\mathbf{c}$, pronounced CTODs, $\mathbf{d}$, large plastic-zone sizes, and $\mathbf{e}$, through ligament plasticity with excessive shear banding and 'tearing-open' of the crack. $\mathbf{f}$, Before unloading, the sample showed a final crack extension of less than $300 \mu \mathrm{m}$ on its surface and a CTOD of more than half a millimeter.

Figure 9. Size-dependent fracture toughness of BMGs. At a ligament width, $b>$ critical bending thickness of a glass, BMGs fail in a generally brittle manner; in this region the plane-strain fracture toughness of the material can be measured reliably using linearelastic fracture mechanics. When $b \sim$ critical bending thickness, the fracture toughness results start to increase, vary significantly, and become sample-size and geometrydependent. If $b<$ critical bending thickness, fracture occurs with fully ductile, noncatastrophic failure with subcritical crack growth ( $R$-curve behavior) and less variability in the toughness results. 


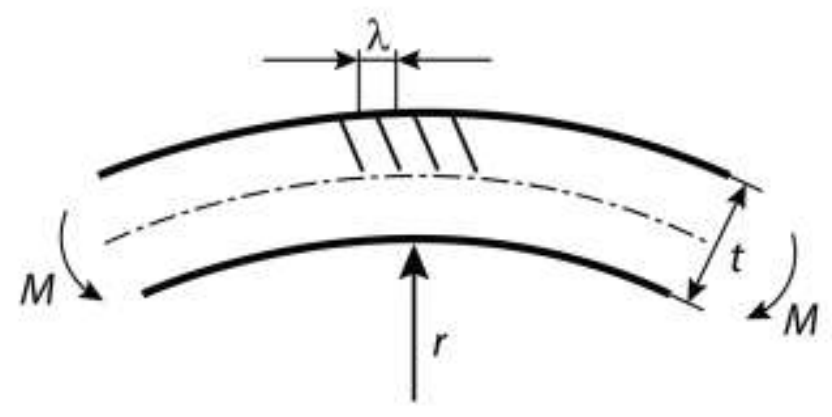

Figure 1. Bending ductility of bulk metallic glasses. Conner et al. [21,22] have shown that below a certain critical thickness, $t$, the spacing of shear bands, $\lambda$, in bulk metallic glass (BMG) samples decreases with increasing bending moment, $M$, and decreasing radius, $r$. This enables BMGs to prevent catastrophic failure through the formation of multiple shear bands resulting in increasing ductility in bending with decreasing thickness. (Figure taken from ref. [59].) 

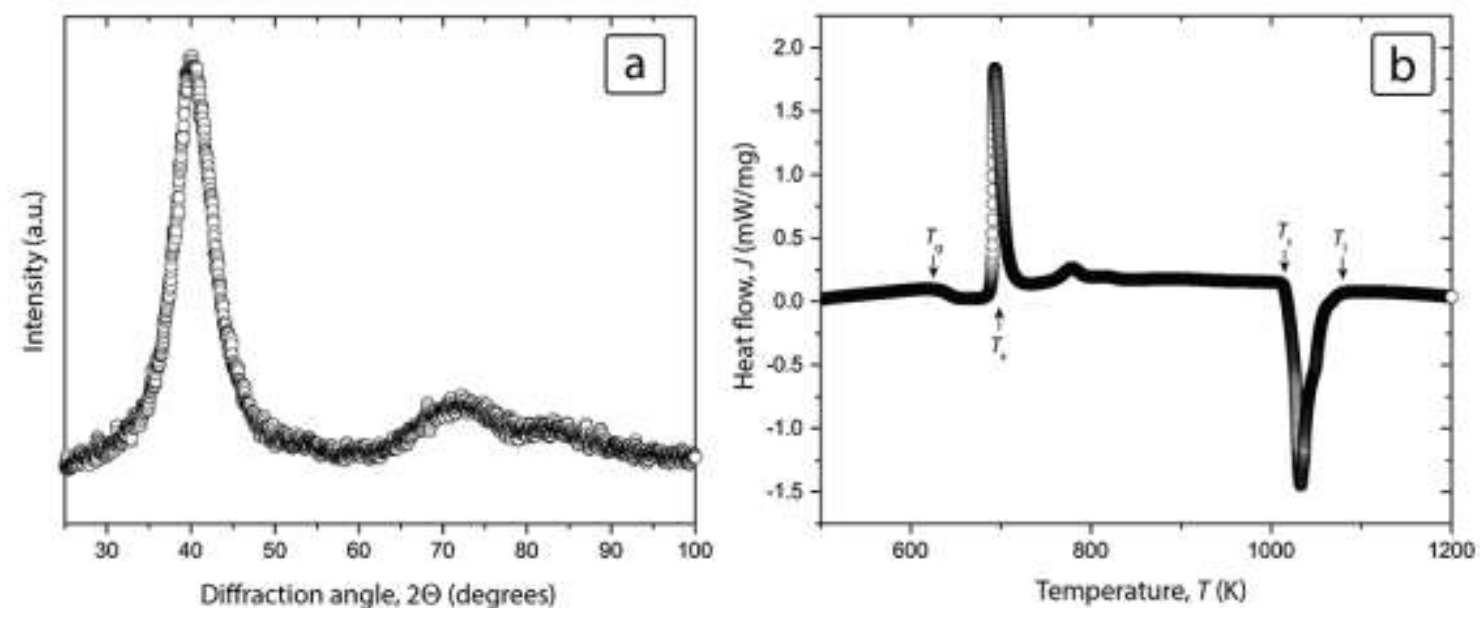

Figure 2. X-ray diffraction (XRD) analysis and differential scanning calorimetry (DSC) of the $\mathrm{Pd}_{77.5} \mathrm{Cu}_{6} \mathrm{Si}_{16.5}$ metallic glass. a, XRD performed at $0.5^{\circ}$ per minute showed the fully amorphous nature of the Pd77.5 $\mathrm{Cu}_{6} \mathrm{Si}_{16.5} \mathrm{BMG}$. $\mathbf{b}$, DSC of the glass performed at a heating rate of $20 \mathrm{~K} \cdot \mathrm{min}^{-1}$ revealed a glass-transition temperature, $T_{\mathrm{g}}=625 \mathrm{~K}$, a crystallization temperature, $T_{\mathrm{x}}=698 \mathrm{~K}$, and a solidus, $T_{\mathrm{s}}=1015 \mathrm{~K}$, and liquidus temperature, $T_{1}=1080 \mathrm{~K}$. 

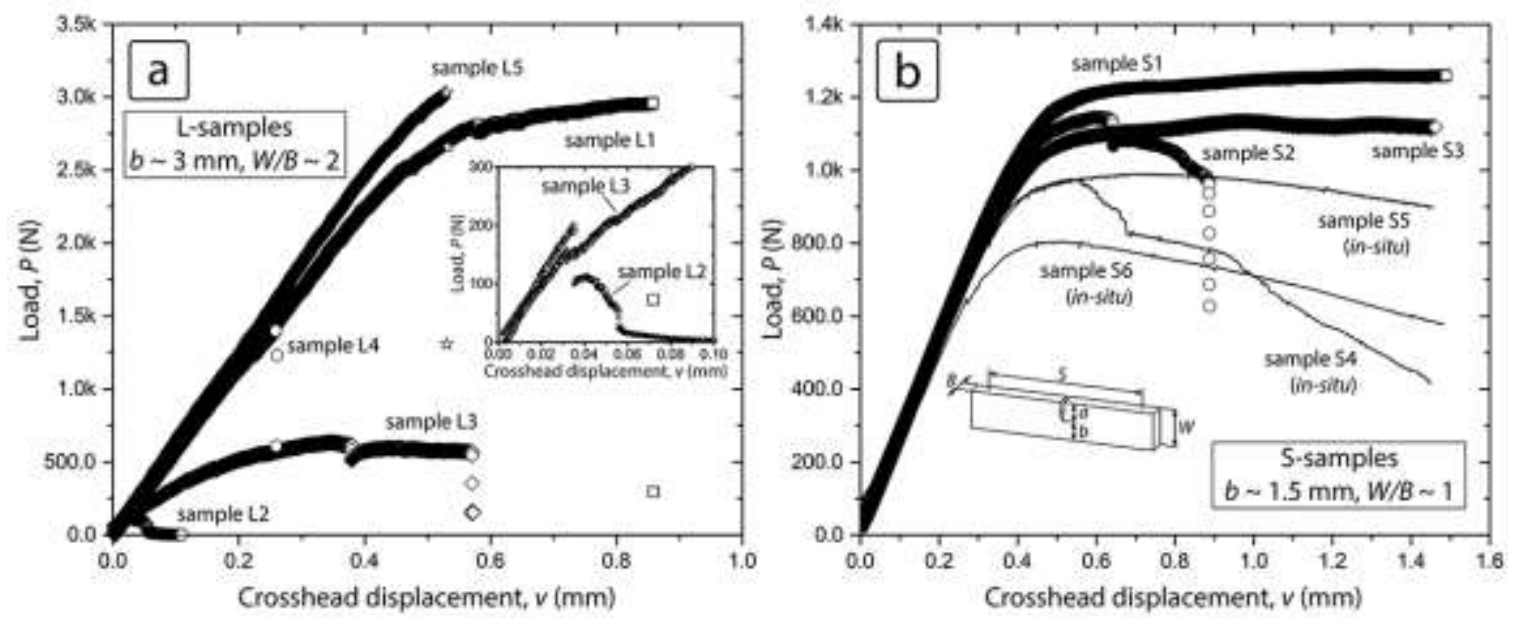

Figure 3. Load-displacement, $P-v$, curves of the Pd-based glass using large-sized standard and small-sized alternative single-edge notched bend, SE(B), samples. $a$, The $P-v$ data of five standard L-samples showed a wide range of failure characteristics from almost ideally linear-elastic failure to significant amounts of plasticity before failure; after multiple load drops final fracture loads were found between about $100 \mathrm{~N}$ (see inset) and more than 3000 N. b, Despite significant load drops of the ex situ loaded sample S2 and the SEM in situ loaded sample S4, none of the six alternative S-samples failed catastrophically. 

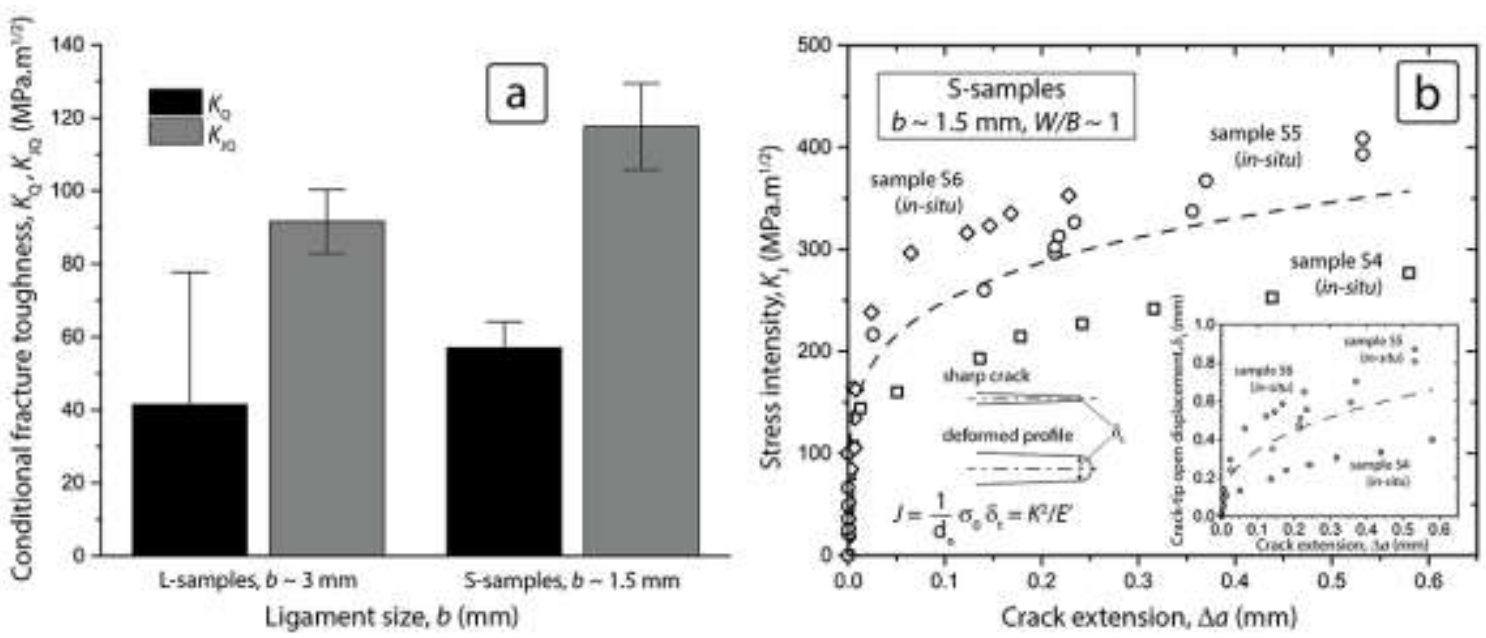

Figure 4. Fracture toughness of the Pd-based BMG samples. a, Mean fracture toughness values of both L-samples and S-samples were significantly lower when calculated using linear-elastic fracture mechanics $\left(K_{\mathrm{Q}}\right)$, as compared to their corresponding nonlinear-elastic fracture toughness values, $K_{\mathrm{JQ}} . \mathbf{b}$, In situ SEM-tested Ssamples showed subcritical crack growth with crack-tip opening displacements (CTODs) up to $1 \mathrm{~mm}$ (see inset) and an increasing crack propagation resistance with crack extension ( $R$-curve behavior). 

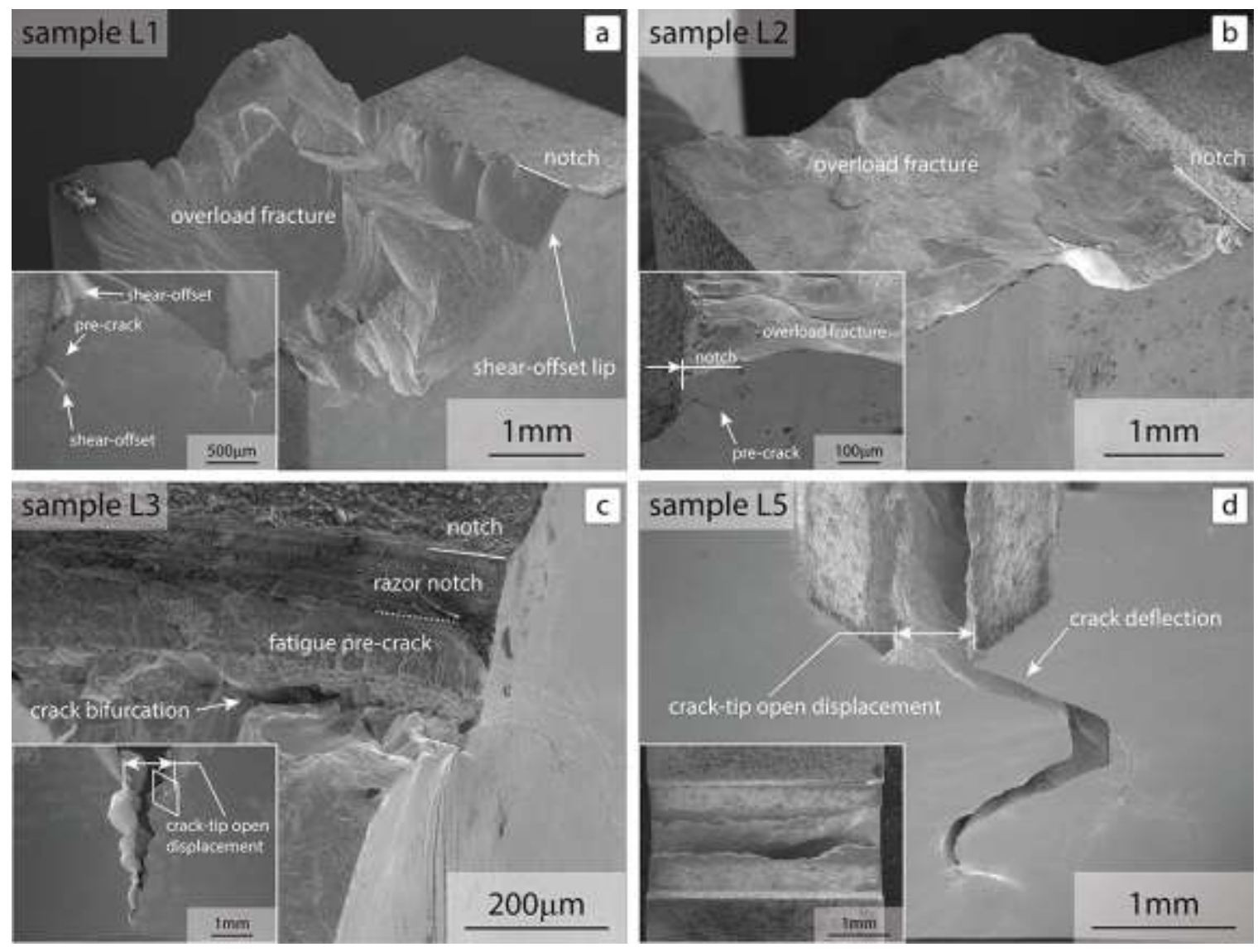

Figure 5. Failure modes of the large-size standard samples. a, Sample L1 failed catastrophically with a highly tortuous crack path whereas $\mathbf{b}$, sample L2 showed a relatively smooth fracture surface along the mode I crack propagation plane. c, Sample L3 did not fail catastrophically; it displayed a serrated but overall straight crack path and showed relatively large CTODs. d, Sample L5, while also not failing catastrophically, showed extreme crack deflection out of the mode I plane and a slightly curved crack front throughout the thickness of sample L5. 

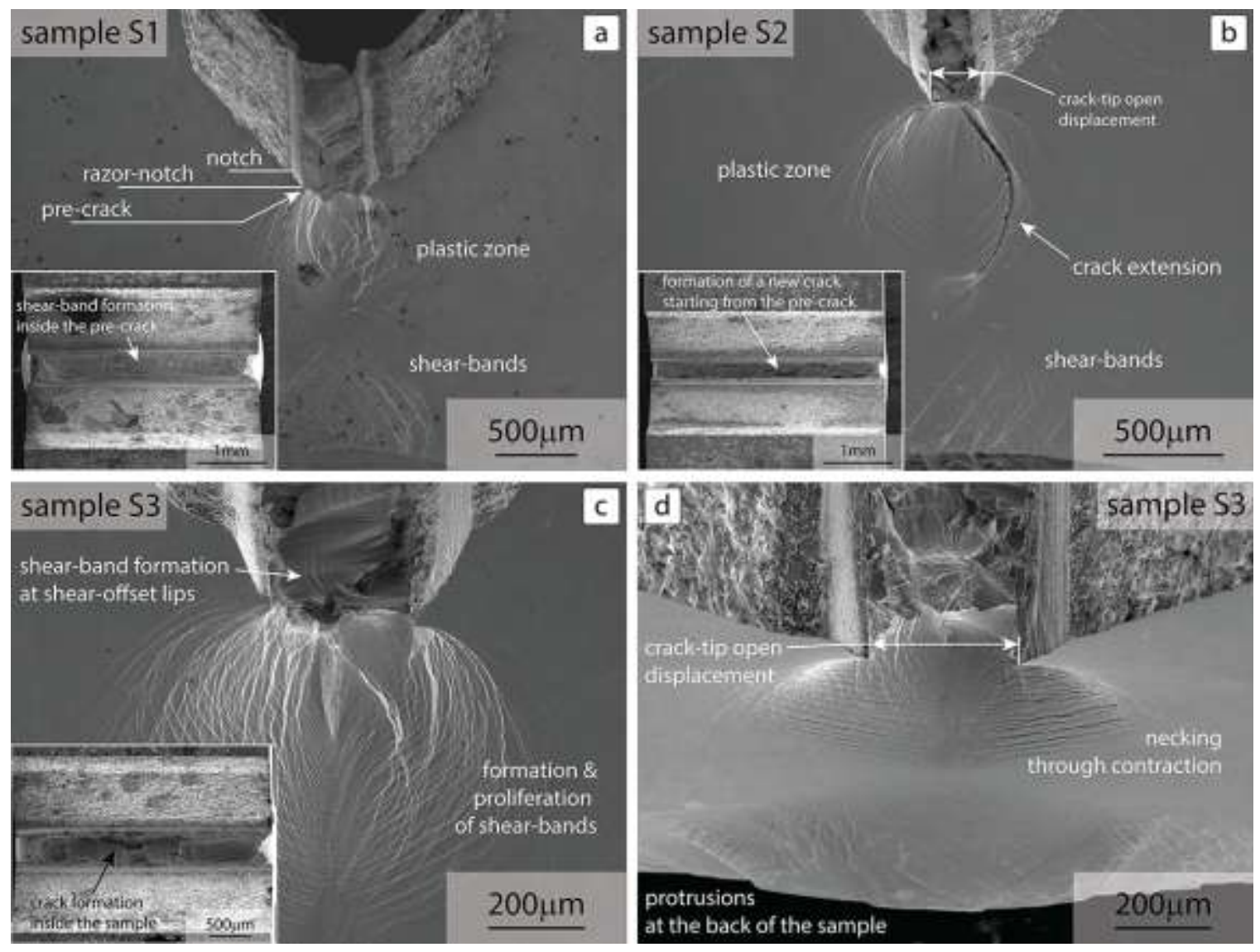

Figure 6. Failure modes of the $e x$ situ tested small-sized alternative samples. a, Sample S1 showed significant formation and proliferation of shear bands from the root of both the notch and the pre-crack. b, Sample S2 showed similar features with the additional formation and propagation of a crack. c, In the case of sample S3, the excessive shear banding resulted in pronounced shear-offset-lips at first crack extensions leading to $\mathbf{d}$, excessive necking through contractions ahead of the crack tip and protrusions at the back of the sample. 

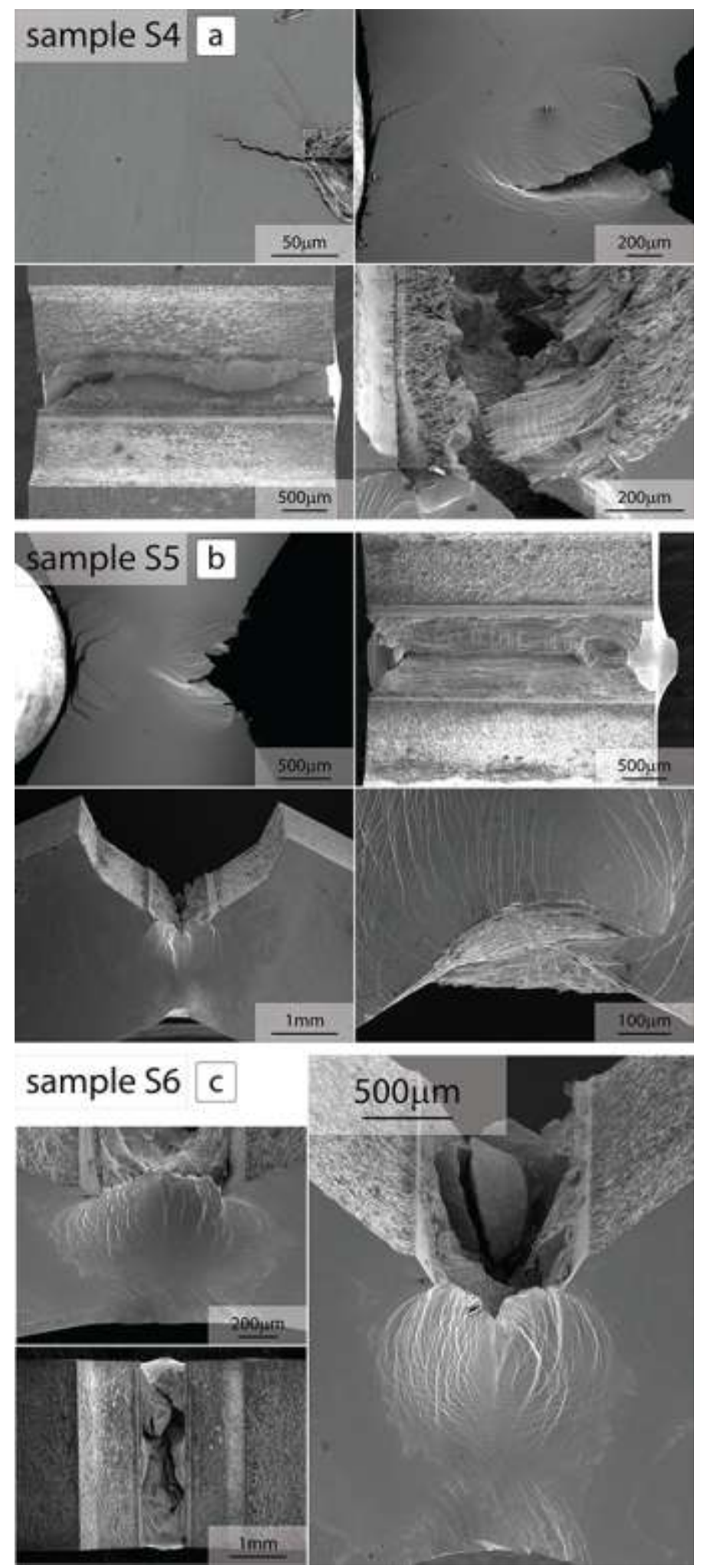

Figure 7. Failure modes of the in situ SEM tested small-sized alternative samples. a, Sample S4 failed by the formation of pronounced crack bifurcation starting from a single pre-crack leading to large CTODs and a slightly curved crack front throughout the 
thickness of the sample. $\mathbf{b}$, Crack extension in sample S5 occurred through the formation of multiple cracks with very large CTODs and pronounced contractions and protrusions. c, Sample S6 showed significant crack tunneling in the center of the sample and a pronounced curvature of the crack front. 

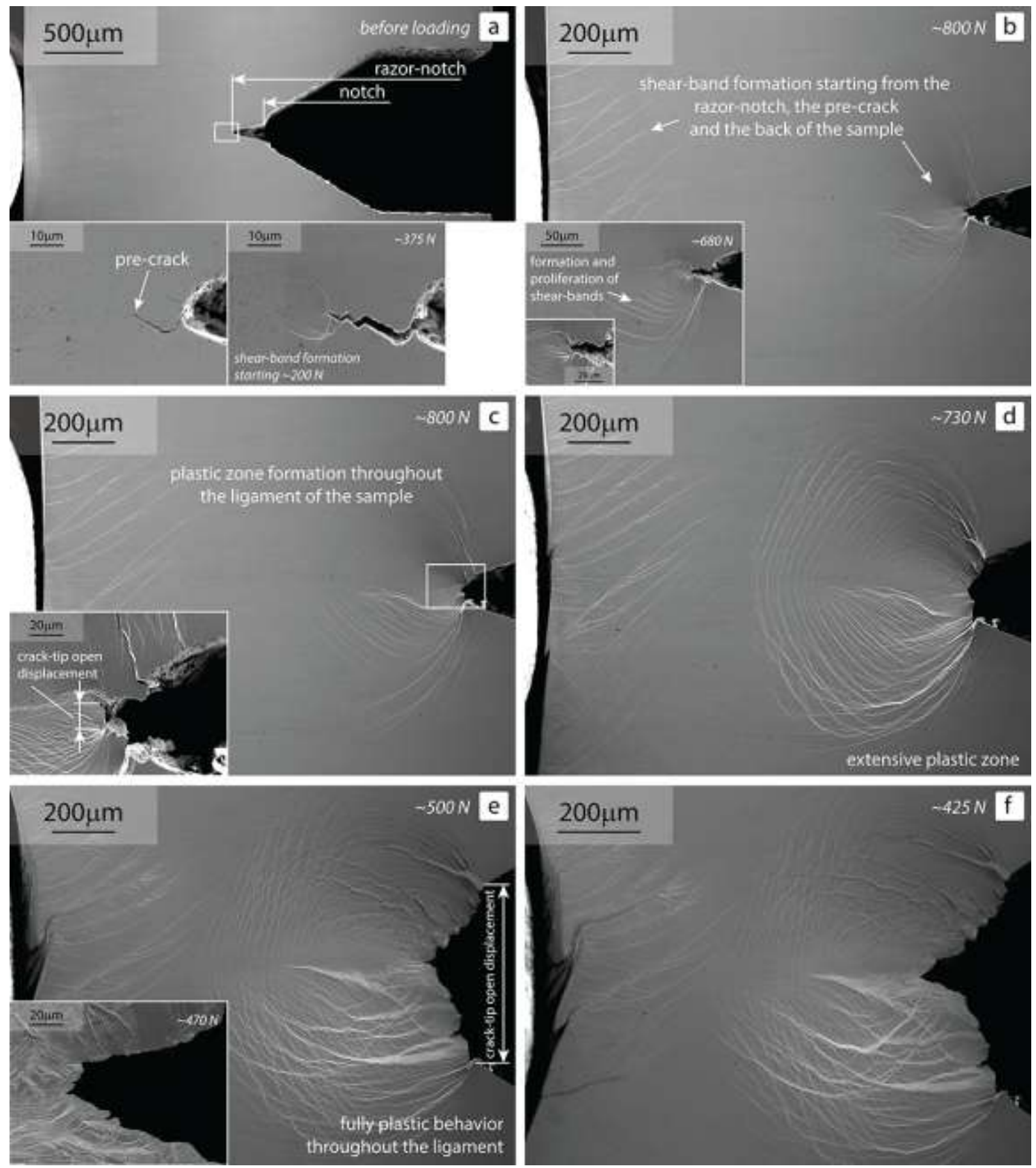

Figure 8. Evolution of failure in the in situ tested sample S6. a, The onset of shear-band formation for the pre-cracked sample occurred around $\sim 200 \mathrm{~N}$ before $\mathbf{b}$, shear bands formed both in the back of the sample and from the root of the razor-notch at a load of $\sim 800 \mathrm{~N}$, leading to $\mathbf{c}$, pronounced CTODs, $\mathbf{d}$, large plastic-zone sizes, and e, through ligament plasticity with excessive shear banding and 'tearing-open' of the crack. $\mathbf{f}$, Before unloading, the sample showed a final crack extension of less than $300 \mu \mathrm{m}$ on its surface and a CTOD of more than half a millimeter. 


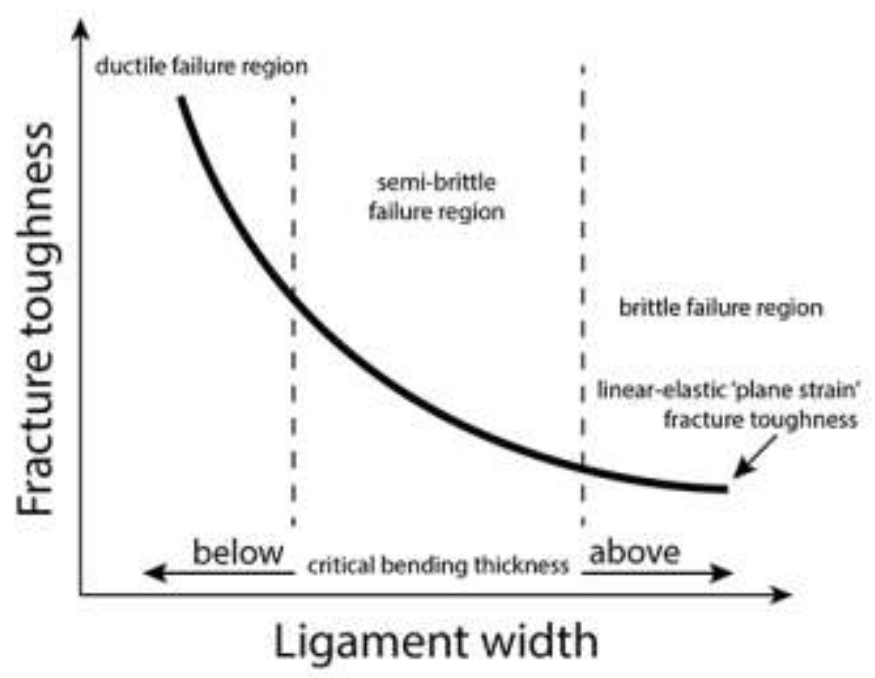

Figure 9. Size-dependent fracture toughness of BMGs. At a ligament width, $b>$ critical bending thickness of a glass, BMGs fail in a generally brittle manner; in this region the plane-strain fracture toughness of the material can be measured reliably using linearelastic fracture mechanics. When $b \sim$ critical bending thickness, the fracture toughness results start to increase, vary significantly, and become sample-size and geometrydependent. If $b<$ critical bending thickness, fracture occurs with fully ductile, noncatastrophic failure with subcritical crack growth ( $R$-curve behavior) and less variability in the toughness results. 